\title{
Elementary steps in acetone condensation reactions catalyzed by aluminosilicates with diverse void structures
}

\author{
Stanley Herrmann and Enrique Iglesia* \\ Department of Chemical and Biomolecular Engineering \\ University of California, Berkeley, CA 94720, USA
}

December 15, 2016

* Corresponding author. E-mail address: iglesia@berkeley.edu (E. Iglesia)

(C) 2016. This manuscript version is made available under the Elsevier user license

http://www.elsevier.com/open-access/userlicense/1.0/ 


\begin{abstract}
:
The unselective nature and ubiquitous deactivation of Brønsted acids in aldol condensations have precluded their practical use and unequivocal mechanistic assessments. $\mathrm{H}_{2}$ and a Pt function are used here to confer stability by scavenging unsaturated intermediates to form stable products, thus allowing kinetic, spectroscopic, and isotopic assessments of elementary steps and their kinetic relevance, confirmed by density functional theory (DFT), for acetone condensation on microporous and mesoporous aluminosilicates (FER, TON, MFI, BEA, FAU, MCM-41). The selective titration of protons with 2,6-di-tert-butyl pyridine during catalysis shows that condensations occur exclusively on protons; the number of titrants required to suppress reactivity measures accessible sites and allows reactivity to be rigorously reported as turnover rates. Infrared spectra show that $\mathrm{H}$-bonded acetone is present at saturation coverages during condensation catalysis. Taken together with rates that depend linearly on acetone pressure and with the absence of H/D kinetic isotope effects, these data indicate that condensation turnovers are mediated by the kinetically-relevant formation of a $\mathrm{C}-\mathrm{C}$ bond via reactions of $\mathrm{H}-$ bonded acetone with another acetone molecule, a conclusion confirmed by DFT-derived free energies along the reaction coordinate. Measured rate constants reflect free energy differences between this transition state and its relevant precursors, a H-bonded and a gaseous acetone. These rate constants (per $\mathrm{H}^{+}$) depend sensitively on size and shape of the confining voids among aluminosilicates of similar acid strength but diverse framework structure. Confinement effects are mediated by van der Waals contacts and are accurately described by energies derived from Lennard-Jones potentials of DFT-derived transition state structures; these energies are ensembleaveraged over all accessible configurations and T-site locations in each aluminosilicate framework. These energy descriptors replace incomplete metrics based solely on the sizes of voids and transition states, which fail to capture differences in reactivity among different confining frameworks.
\end{abstract}

Keywords: aldol condensation mechanism; solid Brønsted acids; confinement effects; density functional theory; van der Waals stabilization 


\section{Graphical Abstract:}

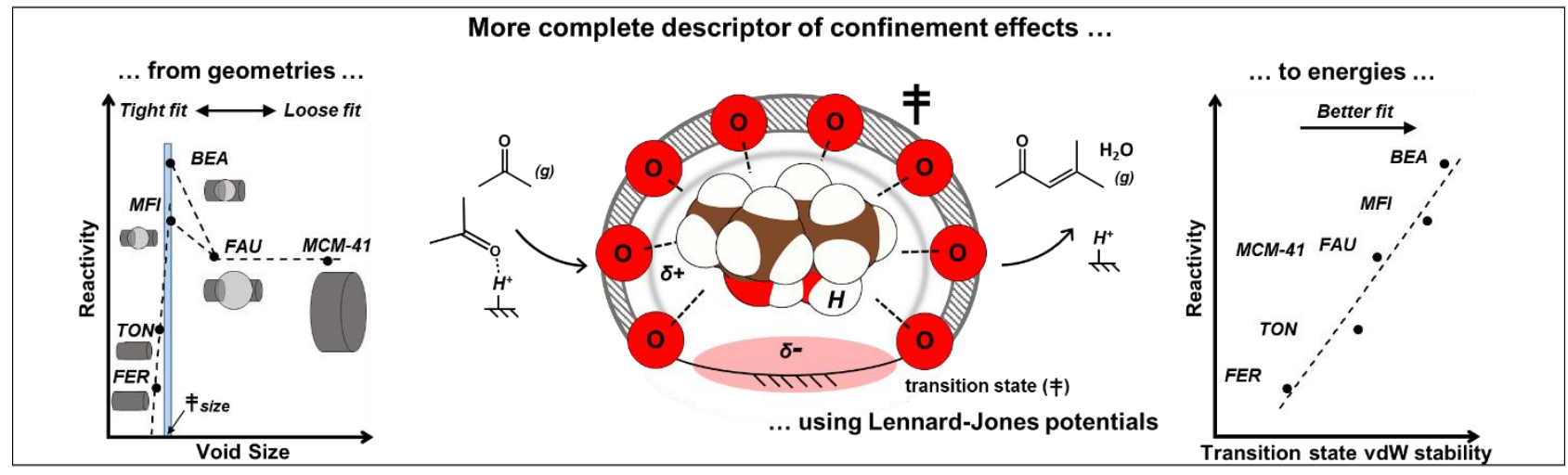




\section{Introduction:}

The conversion of biomass-derived oxygenates to more valuable chemicals and fuels requires precise mechanistic details of the surface reactions that remove $\mathrm{O}$-atoms and form new C-C bonds [1]. These oxygenates are derived from biomass via hydrolysis [2], pyrolysis [3, 4], or fermentation [5] processes; they differ, often significantly, from the fuels and chemicals currently used in their boiling ranges and oxygen content. Aldol condensation reactions, such as those depicted in Scheme 1, form new C-C bonds and reject O-atoms as $\mathrm{H}_{2} \mathrm{O}$, thus increasing the energy density and the boiling point range of biomass-derived oxygenates [1].

Scheme 1: Aldol condensation reaction pathways on acid or base catalysts $\left(-\mathrm{R}_{\mathrm{i}}=\mathrm{C}_{n} \mathrm{H}_{2 \mathrm{n}+1}(\right.$ alkyl) or $\mathrm{H}, \mathrm{i}$ $=1-4)$.

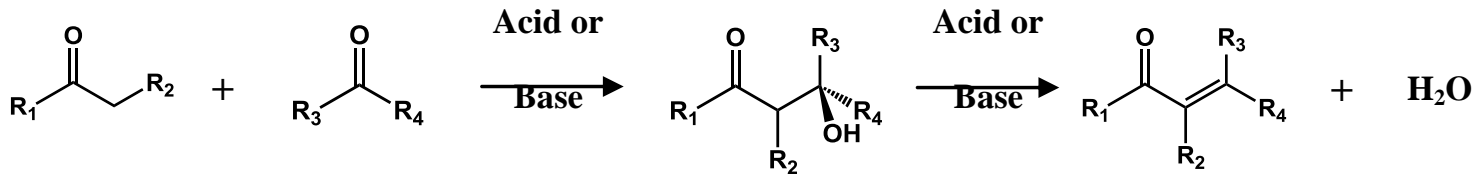

Solid catalysts used for aldol condensation, such as metal oxides [6-8], metals [9], and Brønsted acids $[10,11]$ allow facile separations of products from catalysts, but are prone to fast deactivation, inhibition by products, and yield losses via secondary reactions. Microporous Brønsted acids provide confining voids of molecular dimensions surrounding acidic protons; such voids can confer unique reactivity and selectivity to these protons, in spite of the similar acid strength of aluminosilicates $[12,13]$, through the selective diffusion of certain reactants and products or the preferential van der Waals stabilization of specific intermediates and transition states. Several zeolites have been reported to catalyze aldol condensations (MFI [10, 11, 14-19], BEA [20, 21], MWW [22], and FAU [14, 19, 23]), but ubiquitous deactivation and inhibition by co-products have precluded unequivocal mechanistic conclusions, making it difficult to assess even what type of acid sites account for condensation turnovers: acidic O-H groups [10], Lewis 
acid sites, such as non-framework Al atoms [19], or both types of acid sites acting in concert [19, 24].

Sequential condensation reactions of $\alpha, \beta$-unsaturated products form arenes $[25,26]$ (e.g. 1,3,5-trimethylbenzene from acetone condensation) that bind strongly onto Brønsted acid active sites, thus preventing those sites from catalyzing additional turnovers [14, 27]. The presence of an intracrystalline Pt function has been reported to inhibit the formation of such arenes by hydrogenating the $\alpha, \beta$-unsaturated intermediates to their saturated alkanone analogs before subsequent reactions [22, 27-30]. The practical implementation of these bifunctional strategies seeks to limit parallel acetone hydrogenation reactions by using $\mathrm{Pt}$, which favors $\mathrm{C}=\mathrm{C}$ over $\mathrm{C}=\mathrm{O}$ hydrogenation $[31,32]$, and low partial pressures of $\mathrm{H}_{2}$; such strategies have led to incomplete inhibition of deactivation processes [22, 27-30], thus precluding kinetic measurements and rigorous assessment of intrinsic reactivities, which require stable catalysts. More effective stabilization requires higher $\mathrm{H}_{2}$ pressures, thus causing the concomitant conversion of acetone to propane via sequential hydrogenation-dehydration-hydrogenation reactions. These bifunctional strategies with excess $\mathrm{H}_{2}$ (10-100 $\mathrm{H}_{2}$ /acetone molar ratio), extracrystalline Pt (mixed physically as $\mathrm{Pt} / \mathrm{SiO}_{2}$ with aluminosilicates), and, in some instances, intracrystalline $\mathrm{Pt}$ (exchanged into aluminosilicate crystals) are used here to allow stable rates during kinetic, isotopic, and infrared measurements.

This study reports kinetic, isotopic, spectroscopic, and theoretical evidence for the identity and kinetic relevance of the elementary steps that mediate acetone condensation on acid forms of aluminosilicates with diverse confining environments (FER, TON, MFI, BEA, FAU, MCM-41). Turnover rates, rigorously determined using the number and type of acid sites from titrations with specific organic bases, allow comparisons of intrinsic reactivity among solid acids. 
These data show that condensation reactions occur exclusively on protons, without detectable contributions from Lewis acid centers. Infrared spectra collected during catalysis show that $\mathrm{H}$ bonded acetone is present at saturation coverages on protons. Measured effects of acetone pressure and of reaction temperature on condensation rates, taken together with theoretical treatments of the proposed elementary steps, are consistent with a sequence involving kinetically-relevant $\mathrm{C}-\mathrm{C}$ bond formation mediated by a bimolecular transition state consisting of $\mathrm{a} \mathrm{C}_{3}$-alkenol and a protonated acetone molecule. The interpretation of turnover rates (per proton) in terms of rate constants for elementary steps allow the benchmarking of measured free energy and enthalpy barriers against density functional theory (DFT) estimates; these DFT methods exploit the recent development of functionals that account for dispersion forces [33, 34], which are essential to describe the stabilization of reactants and transition states by confinement within aluminosilicates with diverse framework voids.

The different reactivities of these aluminosilicates reflect differences in Gibbs free energy barriers between $\mathrm{H}$-bonded acetone species and the relevant transition state (TS); these differences are sensitive to the structure of the void environment surrounding the active protons. We show here that rate constants increase as the size of the TS approaches that of the largest cavity diameter [35] in a framework, a heuristic geometric descriptor of the confining voids. Such qualitative descriptions fail to account for the non-spherical geometries of TS and void structures and for the details of their van der Waals contacts; consequently, such a descriptor cannot account for the different rate constants on MFI and BEA, two frameworks with similar largest cavity diameters ( 0.70 and $0.69 \mathrm{~nm}$, respectively).

The void environment surrounding the active acid sites stabilizes the relevant organic moieties, intermediates and transition states, involved in elementary steps through van der Waals 
interactions that depend on the "fit" between the void and these organic species. This study reports a method to determine energy metrics that replace the heuristic geometric descriptors mentioned above. These methods estimate van der Waals stabilization energies $\left(E_{\mathrm{vdW}}\right)$ for each void-organic moiety pair by enumerating individual interactions between each framework Oatom and each atom in the organic moiety. The DFT-optimized structure of each organic moiety, at the T12 site in MFI, is transferred to all T-site locations in each framework (FER, TON, MFI, BEA, FAU), and two-atom Lennard-Jones potentials are used to sample a large number of different orientations (> $10^{3}$ at each T-site location). These $E_{\mathrm{vdW}}$ values at each T-site location are then ensemble-averaged $\left(\left\langle\Delta E_{\mathrm{vdW}}\right\rangle\right)$ over all T-sites of a given framework, for each TS and precursor, in order to compare with measured rate constants. These energy metrics, $\left\langle\Delta E_{\mathrm{vdw}}\right\rangle$, rigorously account for the diversity of void environments within and among frameworks and measured condensation rate constants. Such $\left\langle\Delta E_{\mathrm{vdW}}\right\rangle$ metrics are general descriptors of the catalytic consequences of void environments and are applicable for reactions that are welldescribed by mechanism-based rate equations and for which DFT-derived confined TS and intermediate structures are known.

\section{Methods}

\subsection{Catalyst synthesis protocols}

$\mathrm{NH}_{4}{ }^{+}$-MFI (Zeolyst, $\mathrm{Si} / \mathrm{Al} \mathrm{l}_{\text {tot }}=16.6,29.2,43.8$, and 168.3), $\mathrm{NH}_{4}{ }^{+}$-BEA (Zeolyst, $\mathrm{Si} / \mathrm{Al}_{\text {tot }}=$ 11.8 and 43.3), $\mathrm{NH}_{4}{ }^{+}$-FER (Zeolyst, $\mathrm{Si}^{-} \mathrm{Al}_{\text {tot }}=10.3$ ), $\mathrm{NH}_{4}{ }^{+}$-TON (prepared by BP p.l.c. according to [36, 37], Si/Al tot $=40.0), \mathrm{NH}_{4}{ }^{+}-\mathrm{MCM}-41$ (Sigma-Aldrich, $\left.\mathrm{Si} / \mathrm{Al}_{\text {tot }}=37.8\right)$ and $\mathrm{SiO}_{2}($ Davison Chemical, Chromatographic Silica Media, CAS: 112926-00-8, $280 \mathrm{~m}^{2} \mathrm{~g}^{-1}, 0.57 \mathrm{~cm}^{3} \mathrm{~g}^{-1}$ pore 
volume) materials were treated in flowing dry air $\left(1.5 \mathrm{~cm}^{3} \mathrm{~g}^{-1} \mathrm{~s}^{-1}\right.$, zero grade, Praxair) by heating to $823 \mathrm{~K}$ (at $0.025 \mathrm{~K} \mathrm{~s}^{-1} ; 5 \mathrm{~h}$ hold). Dealuminated $\mathrm{H}-\mathrm{FAU}\left(\mathrm{FAU}, \mathrm{Si} / \mathrm{Al}_{\text {tot }}=7.5\right.$ ) was prepared using methods reported in the LZ-210 patent for the selective extraction of some non-framework $\mathrm{Al}$ atoms [38, 39]. Si, Al, and $\mathrm{Na}$ contents were measured by inductively-coupled plasma atomic emission spectroscopy (ICP-AES; Galbraith Laboratories). The nomenclature and provenance of the samples used and their $\mathrm{Si} / \mathrm{Al}, \mathrm{Al} / \mathrm{unit}$ cell, and $\mathrm{H}^{+} / \mathrm{Al}$ ratios are listed in Table 1 . The largest inscribed sphere (largest cavity diameter) and the largest sphere that can traverse each framework (pore-limiting diameter) derived from crystallographic data [35] are also shown in Table 1.

Table 1: Zeolite and mesoporous aluminosilicate samples

\begin{tabular}{|c|c|c|c|c|c|c|c|}
\hline Zeolite & Provenance & $\begin{array}{l}\mathrm{Si} / \mathrm{Al} \\
\text { ratio }^{\mathrm{a}}\end{array}$ & $\begin{array}{c}\mathrm{Al} / \\
\text { unit cell }^{\mathrm{b}}\end{array}$ & $\mathbf{H}^{+} / \mathbf{A l}$ & $\mathbf{H}^{+} / \mathbf{A l}^{\mathrm{e}}$ & $\begin{array}{l}\mathbf{d}_{\mathrm{LCD}}{ }^{\mathbf{f}} \\
(\mathbf{n m})\end{array}$ & $\begin{array}{l}\mathbf{d}_{\text {PLD }}{ }^{g} \\
(\mathbf{n m})\end{array}$ \\
\hline MFI-1 & Zeolyst & 16.6 & 5.47 & $0.65^{\mathrm{c}}$ & 0.52 & 0.70 & 0.50 \\
\hline MFI-2 & Zeolyst & 29.2 & 3.18 & $0.77^{\mathrm{c}}$ & 0.72 & 0.70 & 0.50 \\
\hline MFI-3 & Zeolyst & 43.8 & 2.14 & $1.03^{\mathrm{c}}$ & 0.89 & 0.70 & 0.50 \\
\hline MFI-4 & Zeolyst & 168.3 & 0.58 & $0.70^{\mathrm{c}}$ & 0.62 & 0.70 & 0.50 \\
\hline BEA-1 & Zeolyst & 11.8 & 4.98 & $0.22^{\mathrm{d}}$ & 0.39 & 0.69 & 0.67 \\
\hline BEA-2 & Zeolyst & 43.3 & 1.44 & $1.04^{\mathrm{d}}$ & 1.30 & 0.69 & 0.67 \\
\hline FER & Zeolyst & 9.5 & 3.19 & $0.35^{\mathrm{c}}$ & 0.73 & 0.70 & 0.53 \\
\hline FAU & [40] & 7.5 & 17.45 & $0.38^{\mathrm{d}}$ & 0.64 & 1.19 & 0.67 \\
\hline MCM-41 & Sigma-Aldrich & 37.8 & -- & $0.42^{\mathrm{d}}$ & -- & $2.50^{\mathrm{h}}$ & $2.50^{\mathrm{h}}$ \\
\hline TON & {$[36,37]$} & 40.0 & 0.59 & -- & $0.88^{*}$ & 0.57 & 0.57 \\
\hline $\begin{array}{ll}\mathrm{a} & \text { ele } \\
\mathrm{b} & \text { fro } \\
\mathrm{c} & \text { fro } \\
\mathrm{d} & \text { fro } \\
& \text { me } \\
\mathrm{e} & \text { frol } \\
& {[44} \\
\mathrm{f} & \text { lar } \\
\mathrm{g} & \text { por } \\
\mathrm{h} & \text { por }\end{array}$ & $\begin{array}{l}\text { ental analysis (I } \\
\mathrm{Si} / \mathrm{Al} \text { ratio and } \\
\text { pyridine titratio } \\
2,6 \text {-di-tert-buty } \\
\text { ods in Section } 2 \\
\text { the amount of } \\
\text { st-cavity diamet } \\
\text { limiting diamete } \\
\text { diameter reporte }\end{array}$ & \multicolumn{3}{|c|}{$\begin{array}{ll}\text { a } & \text { elemental analysis (ICP-AES; Galbraith Laboratories). } \\
\text { b } & \text { from } \mathrm{Si} / \mathrm{Al} \text { ratio and framework crystal structure [41]. } \\
\text { c from pyridine titrations during } \mathrm{CH}_{3} \mathrm{OH} \text { dehydration at } 433 \mathrm{~K} \mathrm{[42].} \\
\text { d from 2,6-di-tert-butylpyridine titrations during acetone condensation at } 473 \mathrm{~K} \text { (Figure 3, } \\
\text { methods in Section 2.3). }\end{array}$} & $\begin{array}{l}3 \mathrm{~K} \text { [42] } \\
\text { ondensat } \\
\text { d sample }\end{array}$ & & igure 3 , \\
\hline
\end{tabular}


$\mathrm{Pt} / \mathrm{SiO}_{2}(2.0 \%$ wt $\mathrm{Pt})$ was prepared by incipient wetness impregnation of $\mathrm{SiO}_{2}($ Davison Chemical) with an aqueous solution of hexacholoroplatinic acid $\left(\mathrm{H}_{2} \mathrm{PtCl}_{6} \cdot\left(\mathrm{H}_{2} \mathrm{O}\right)_{6}\right.$, Aldrich, CAS: 16941-12-1). The impregnated powders were treated in dry air $\left(1.5 \mathrm{~cm}^{3} \mathrm{~g}^{-1} \mathrm{~s}^{-1}\right.$, zero grade, Praxair) by heating to $383 \mathrm{~K}$ (at $0.033 \mathrm{~K} \mathrm{~s}^{-1} ; 3 \mathrm{~h}$ hold) and then to $873 \mathrm{~K}$ (at $0.033 \mathrm{~K} \mathrm{~s}^{-1} ; 5 \mathrm{~h}$ hold) and cooled to ambient temperature. Samples were then exposed to $10 \% \mathrm{H}_{2} / \mathrm{He}\left(0.8 \mathrm{~cm}^{3} \mathrm{~g}^{-1}\right.$ $\mathrm{s}^{-1}$, certified standard, Praxair) and heated to $873 \mathrm{~K}$ (at $0.083 \mathrm{~K} \mathrm{~s}^{-1} ; 2 \mathrm{~h}$ hold), cooled to ambient temperature in $\mathrm{He}\left(0.8 \mathrm{~cm}^{3} \mathrm{~g}^{-1} \mathrm{~s}^{-1}\right.$, UHP, Praxair), and then contacted with $1 \% \mathrm{O}_{2} / \mathrm{He}\left(0.8 \mathrm{~cm}^{3} \mathrm{~g}^{-1}\right.$ $\mathrm{s}^{-1}$, certified standard, Praxair) at ambient temperature for $0.5 \mathrm{~h}$ to passivate the samples before exposure to ambient air.

Pt cations were exchanged into H-BEA zeolite (Pt/BEA-1) by dropwise addition of a tetraammineplatinum(II) nitrate solution $\left(0.025 \mathrm{M}\right.$, $\left[\mathrm{Pt}\left(\mathrm{NH}_{3}\right)_{4}\right]\left(\mathrm{NO}_{3}\right)_{2}$, Sigma-Aldrich, CAS: 20634-12-2) to an aqueous suspension of zeolite crystals $\left.\left(100 \mathrm{~cm}^{3} \mathrm{H}_{2} \mathrm{O} \text { (g zeolite }\right)^{-1}\right)$ to achieve a nominal Pt content of $1.0 \% \mathrm{wt}$; the suspension was stirred at ambient temperature for $12 \mathrm{~h}$. Solids were recovered by vacuum filtration, rinsed with deionized water $(>17.6 \Omega \mathrm{cm}$ resistivity, $\left.1000 \mathrm{~cm}^{3} \mathrm{H}_{2} \mathrm{O}(\mathrm{g} \text { zeolite })^{-1}\right)$ and treated in dry air $\left(1.5 \mathrm{~cm}^{3} \mathrm{~g}^{-1} \mathrm{~s}^{-1}\right.$, zero grade, Praxair) by heating to $383 \mathrm{~K}$ (at $0.033 \mathrm{~K} \mathrm{~s}^{-1} ; 3 \mathrm{~h}$ hold) and then to $723 \mathrm{~K}$ (at $0.025 \mathrm{~K} \mathrm{~s}^{-1} ; 4 \mathrm{~h}$ hold). These samples were then cooled to $573 \mathrm{~K}$ and held for $3 \mathrm{~h}$ in flowing $10 \% \mathrm{H}_{2} / \mathrm{He}\left(0.8 \mathrm{~cm}^{3} \mathrm{~g}^{-1} \mathrm{~s}^{-1}\right.$, certified standard, Praxair) before cooling to ambient temperature and exposing the samples for $0.5 \mathrm{~h}$ to flowing $1 \% \mathrm{O}_{2} / \mathrm{He}\left(0.8 \mathrm{~cm}^{3} \mathrm{~g}^{-1} \mathrm{~s}^{-1}\right.$, certified standard, Praxair).

\subsection{Catalytic rate and selectivity measurements}

Condensation rates were measured at $463-483 \mathrm{~K}$ and low acetone conversion $(<5 \%)$ to maintain differential reaction conditions. Samples containing extracrystalline Pt as physical mixtures (e.g. MFI-1 $+\mathrm{Pt} / \mathrm{SiO}_{2}$ ) were prepared by crushing the mixture of aluminosilicate 
crystals and $\mathrm{Pt} / \mathrm{SiO}_{2}$ into small aggregates $(<180 \mu \mathrm{m})$ with a mortar and pestle for $0.25 \mathrm{~h}$. Powders were pressed into wafers (690 bar, $0.1 \mathrm{~h}$ ), crushed, and sieved to retain $180-250 \mu \mathrm{m}$ aggregates. These aggregates $(0.020-0.200 \mathrm{~g})$ were held within a tubular quartz reactor $(7.0 \mathrm{~mm}$ i.d.) and kept at constant temperature using a three-zone resistively-heated furnace (Applied Test Systems Inc., model number 3210) controlled by three independent temperature controllers (Watlow Series 988); temperatures were measured using a K-type thermocouple (Omega) in contact with the outer surface of the quartz reactor at the midpoint along the catalyst bed.

Aluminosilicates (Table 1) were treated in flowing dry air $\left(83.3 \mathrm{~cm}^{3} \mathrm{~g}^{-1} \mathrm{~s}^{-1}\right.$, extra dry, Praxair) by heating to $818 \mathrm{~K}$ (at $0.025 \mathrm{~K} \mathrm{~s}^{-1} ; 2 \mathrm{~h}$ hold) and then cooled to reaction temperatures. Aluminosilicates were separately treated at similar conditions before mixing with $\mathrm{Pt} / \mathrm{SiO}_{2}$. $\mathrm{Pt}-$ containing samples-physical mixtures and Pt-exchanged mixtures-were exposed to $10 \%$ $\mathrm{H}_{2} / \mathrm{He}\left(83.3 \mathrm{~cm}^{3} \mathrm{~g}^{-1} \mathrm{~s}^{-1}\right.$, certified standard, Praxair), heated to $623 \mathrm{~K}$ (at $0.025 \mathrm{~K} \mathrm{~s}^{-1} ; 2 \mathrm{~h}$ hold), and then cooled to reaction temperatures before condensation rate measurements.

Catalyst deactivation was described using first-order deactivation kinetics [45]:

$$
r(t)=r(0) \cdot \exp \left(-k_{\mathrm{d}} t\right)
$$

where $r$ is the condensation rate, $t$ is the time on stream, and $k_{\mathrm{d}}$ is the effective first-order deactivation rate constant. Such first-order deactivation processes require that sites deactivate at rates independent of the prevalent concentration of reactants and products. Here, we consider rates to have reached constant values when first-order deactivation constants $\left(k_{\mathrm{d}}\right)$ are smaller than $0.05 \mathrm{ks}^{-1}$. 
Acetone ( $\geq 99.9 \%$, Sigma-Aldrich) was introduced into $\mathrm{He}$ (UHP, Praxair) and $\mathrm{H}_{2}$ (UHP, Praxair) streams using a liquid syringe pump (Legato 100, KD Scientific) and vaporized in transfer lines kept at $403 \mathrm{~K}$. Inlet and effluent streams were analyzed by gas chromatography (GC; Agilent 6890A) using flame ionization detection (FID) after chromatographic separation (HP-1 column, Agilent). Molecular speciation was confirmed using mass spectrometry (MKS Spectra Minilab) and known standards. Retention times and response factors were determined from known concentrations of these compounds: acetone ( $\geq 99.9 \%$, Sigma-Aldrich), diacetone alcohol ( $\geq 98 \%$, Santa Cruz Biotechnology), mesityl oxide (98\%, Spectrum Chemical), isobutene (99.0\%, Praxair), acetic acid ( $\geq 99.99 \%$, Sigma Aldrich), 1,3,5-trimethylbenzene (98\%, SigmaAldrich), and methyl isobutyl ketone (99.5\%, ACROS Organics). Isotopic experiments, using acetone- $\mathrm{d}_{6}\left(99.9 \%\right.$, Sigma-Aldrich) and $\mathrm{D}_{2}(99.8 \%$, Specialty Gases of America), were performed to measure H/D kinetic isotope effects $(K I E)$ :

$$
K I E=\frac{k_{H}}{k_{D}}
$$

where $k_{H}$ and $k_{D}$ denote the first-order condensation rate constants for undeuterated and perdeuterated acetone in the presence of $\mathrm{H}_{2}$ and $\mathrm{D}_{2}$, respectively.

Diacetone alcohol (DA), the initial acetone condensation product, was not detected among reaction products because of its unfavorable thermodynamics and fast dehydration to mesityl oxide (MO) and $\mathrm{H}_{2} \mathrm{O}$, which lead to DA concentrations far below chromatographic detection limits $\left(3.5 \times 10^{-13}-5.6 \times 10^{-9} \mathrm{~Pa} \mathrm{DA}\right.$, Supporting Information $\mathrm{S} 1 ; 0.05 \mathrm{~Pa}$ DA detection limit).

\subsection{Infrared spectra during condensation catalysis}


Infrared spectra were measured in transmission mode using a Nicolet NEXUS 670 spectrometer equipped with a Hg-Cd-Te (MCT) detector by averaging 64 scans in the 4000-400 $\mathrm{cm}^{-1}$ spectral range with $2 \mathrm{~cm}^{-1}$ resolution. Samples $(5-15 \mathrm{mg}$ ) were pressed (690 bar, $0.1 \mathrm{~h}$ ) into self-supporting wafers $\left(3.2 \mathrm{~cm}^{2}\right)$ and held within a quartz vacuum cell equipped with $\mathrm{NaCl}$

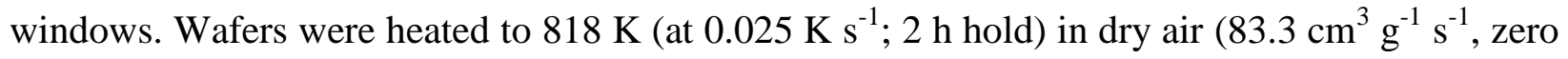
grade, Praxair) and cooled to reaction temperature. Acetone (0.04-2.0 kPa) was injected into a He stream at $403 \mathrm{~K}$ using a liquid syringe pump (KDS-100, KD Scientific). All spectra were normalized by the intensity of the Si-O-Si bands $\left(2100-1750 \mathrm{~cm}^{-1}\right)$.

\subsection{Measurements of the number and type of active sites by titrations with probe molecules}

The number of accessible protons on BEA-1, BEA-2, FAU, and MCM-41 samples were measured by titration with 2,6-di-tert-butyl pyridine (DTBP; >97\%, Sigma-Aldrich) during acetone condensation on Pt-containing samples. DTBP (0.1-1.0 Pa) was introduced after condensation rates reached steady-state values (Section 2.2). DTBP concentrations in the effluent were measured by the chromatographic protocols described above and the number of protons were determined by assuming a 1:1 DTBP: $\mathrm{H}^{+}$ratio. Proton counts on MFI and TON were determined by $\mathrm{NH}_{3}$ evolution from their $\mathrm{NH}_{4}$-exchanged forms because DTBP cannot diffuse through the microporous channels and access intracrystalline protons [43, 44]. The proton counts on FER were determined by titration with pyridine (99.8\%, Sigma-Aldrich) [42] in order to titrate only protons in the $0.53 \mathrm{~nm}$ straight channels [35], which are accessible to acetone $(0.50$ $\mathrm{nm}$, kinetic diameter [46]), but not those in the $0.70 \mathrm{~nm}$ cages [35], which can only be accessed via $0.33 \mathrm{~nm}$ channels and are therefore inaccessible to acetone reactants [47]. All proton locations in the FER framework are accessible to $\mathrm{NH}_{4}{ }^{+}$cations and are counted when using $\mathrm{NH}_{3}$ evolution from $\mathrm{NH}_{4}$-exchanged FER (Table 1). The proton counts from pyridine titration and 
$\mathrm{NH}_{3}$ evolution from $\mathrm{NH}_{4}$-exchanged samples are similar on MFI (Table 1) because all protons can be accessed by both pyridine and $\mathrm{NH}_{4}{ }^{+}$cations.

\subsection{Theoretical treatments of transition states and adsorbed intermediates involved in condensation elementary steps occurring within confined environments}

The structures and energies of MFI aluminosilicates, gaseous and bound species, and transition states were calculated using periodic plane-wave DFT methods, as implemented in the Vienna $a b$ initio simulation package (VASP 5.35) [48-51]. Valence electronic states were described using planewaves with an energy cutoff of $396 \mathrm{eV}$. Projector augmented-wave potentials (PAW5) $[52,53]$ were used to describe interactions among valence electrons and atom cores. Exchange and correlation energies were described by the revised Perdew-Burke-Ernzerhof (RPBE) form of the generalized gradient approximation (GGA) [54, 55] with an empirical dispersive energy correction (DFT-D3) and Becke-Johnson (BJ) damping incorporated at each optimization iteration $[33,34]$ to account for van der Waals forces that influence the stability of confined species. Calculations were also performed using the vdW-DF2 functional [56-59], which incorporates van der Waals interactions into the structure optimization. A $(1 \times 1 \times 1) \gamma$ centered $k$-point mesh was used to sample the first Brillouin zone. Electronic wavefunctions were optimized until changes in energy between successive iterations were $\leq 1 \times 10^{-6} \mathrm{eV}$, and the

structures were relaxed until the forces on all unconstrained atoms were $\leq 0.05 \mathrm{eV} \AA^{-1}$. Atomic coordinates and unit cell parameters $\left(2.0022 \times 1.9899 \times 1.3383 \mathrm{~nm}^{3}\right.$ and $\left.\alpha=\beta=\gamma=90^{\circ}\right)$ for MFI structure were obtained from crystallographic data [60]. Brønsted acid sites were introduced into the model of the solids by replacing a Si-atom with an Al-atom at the channel intersection (T12, Scheme 2, which includes H-bonded acetone; numbered according to convention [61]) [42, 43] to give a model solid with a Si/Al ratio of 95 (1.0 Al/unit cell). All molecular structures depicted 
here used an open-source software package for geometric representation (Visualization for Electronic and Structural Analysis; VESTA [62]).

Scheme 2: $\mathrm{Al}$ at $\mathrm{T} 12$ location in MFI with acetone $\mathrm{H}$-bonding to the proton (O11).

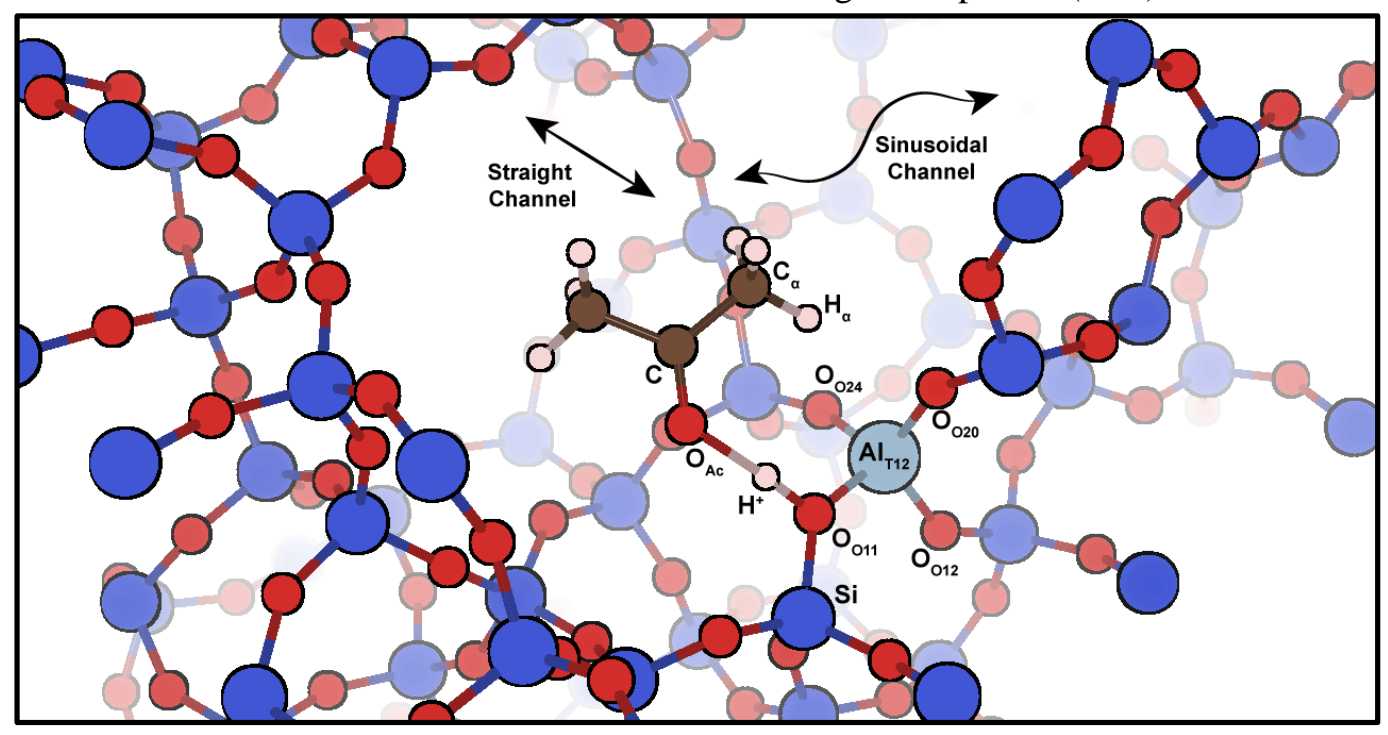

Nudged elastic band (NEB) methods [63] were used to determine the minimum energy paths between reactants and products for each elementary step; structures near the maximum energy along the reaction coordinate were used to isolate transition states using Henkelman dimer methods [64]. Electronic energy changes in NEB calculations were converged to $<1 \times 10^{-4}$ $\mathrm{eV}$ and forces on each unconstrained atom were minimized to $<0.3 \mathrm{eV} \AA^{-1}$. Dimer calculations of all TS structures used the same convergence criteria as those in the optimization simulations described above.

Frequency calculations were performed on all optimized structures to determine zeropoint vibrational energies $(Z P V E)$, vibrational enthalpies and free energies $\left(H_{v i b}\right.$ and $\left.G_{v i b}\right)$, and, in the case of gaseous molecules, translational and rotational enthalpies $\left(H_{\text {trans }}\right.$ and $\left.H_{\text {rot }}\right)$ and free energies $\left(G_{\text {trans }}\right.$ and $\left.G_{r o t}\right)$. Low-frequency modes $\left(<150 \mathrm{~cm}^{-1}\right)$ of weakly-bound intermediates and 
transition states lead to significant errors in vibrational free energies [65]; these modes were replaced by translational and rotational free energies assumed to retain a fraction $(0.70)$ of the translational and rotational free energies of their gaseous analogs, as suggested by measured entropies of adsorption on oxide surfaces [66]. These corrections for zero-point vibrational energies, translations, rotations, and vibrations were added to the DFT-derived electronic energies $\left(E_{0}\right)$ to calculate enthalpies:

$$
H=E_{0}+Z P V E+H_{\text {vib }}+H_{\text {trans }}+H_{\text {rot }}
$$

and free energies:

$$
G=E_{0}+Z P V E+G_{v i b}+G_{\text {trans }}+G_{\text {rot }}
$$

The Gibbs free energies for transition states $\left(G^{\ddagger}\right)$ and their relevant precursors $\left(G^{p}\right)$ were calculated at the T12 site of MFI to estimate free energy barriers $\left(\Delta G_{T 12}^{\ddagger}\right)$ :

$$
\Delta G_{T 12}^{\ddagger}=G_{\mathrm{T} 12}^{\ddagger}-\sum_{p} G_{\mathrm{T} 12}^{p}
$$

Ensemble (exponential) averaging of DFT-estimated free energy barriers was used to account for the distinct binding locations at each of the four vicinal framework O-atoms when structures contain covalent bonds to the framework. Ensemble-averaged Gibbs free energy barriers $(\langle\Delta G\rangle)$ were calculated using (derivation in SI, S2):

$$
\langle\Delta G\rangle=-k_{B} T \ln \left(\sum_{i=1}^{N_{\text {site }}} \exp \left(-\frac{\Delta G_{i}}{k_{B} T}\right) \mathrm{P}_{\text {site }, i}\right)
$$

where $k_{B}$ is the Boltzmann constant, $N_{\text {site }}$ is the number of distinct sites (e.g. $N_{\text {site }}=4$ for the distinct structures of acetone H-bonding with the proton located at each of the four O-atoms 
bound to $\mathrm{Al}$ ), and $\mathrm{P}_{\text {site }, i}$ is the probability of site $i$ occurring (e.g. in the example of $\mathrm{H}$-bonded acetone, this is the probability of the proton being bound at each of the four O-atoms bound to the Al). The $\mathrm{P}_{\text {site }, i}$ of equilibrated states was calculated by a Boltzmann average of the free energy of each site $\left(G^{\text {site }}\right)$ :

$$
\mathrm{P}_{\text {site }, i}=\frac{\exp \left(-\frac{G_{i}^{\text {site }}}{k_{B} T}\right)}{\sum_{j=1}^{N_{\text {site }}} \exp \left(-\frac{G_{j}^{\text {site }}}{k_{B} T}\right)}
$$

Such ensemble averaging is required for a rigorous evaluation of the Gibbs free energy barriers for reaction $\left(\left\langle\Delta G_{\mathrm{T} 12}^{\ddagger}\right\rangle\right.$; barrier for the TS $(\ddagger)$ at the T12 site) and adsorption $\left(\left\langle\Delta G_{\mathrm{Ac} *}\right\rangle\right.$; free energy difference for acetone adsorption), which are used to calculate, respectively, rate constants $\left(k_{\mathrm{T} 12}\right)$ $[67,68]:$

$$
k_{\mathrm{T} 12}=\frac{k_{B} T}{h} \exp \left(-\frac{\left\langle\Delta G_{\mathrm{T} 12}^{\ddagger}\right\rangle}{k_{B} T}\right)
$$

where $h$ is Planck's constant, and adsorption constants (e.g. acetone adsorption constant $\left.\left(K_{\mathrm{Ac}}\right)\right)$ :

$$
K_{\mathrm{Ac}}=\exp \left(-\frac{\left\langle\Delta G_{\mathrm{Ac} *}\right\rangle}{k_{B} T}\right)
$$

These acetone adsorption constants are then used to calculate the fraction of the protons occupied by acetone $\left(\theta_{\text {Ac }}\right)$ :

$$
\theta_{A c}=\frac{K_{\mathrm{Ac}}(A c)}{1+K_{\mathrm{Ac}}(A c)}
$$

These DFT-derived kinetic and thermodynamic constants, as well as free energy and enthalpy barriers, at the T12 site in MFI are compared with measured values on MFI to confirm or falsify mechanistic hypotheses. 


\subsection{Sampling of the intermediates and transition states at different locations within confining voids}

Theoretical treatments, described above, provide molecular structures of transitions states and relevant precursors, which allow geometric estimates (e.g. size and shape) of these species; these geometric estimates are used here to probe the consequences of confinement within voids of molecular dimensions for condensation turnovers. In one strictly geometric approach, we define the size of organic moieties and voids in terms of a characteristic distance. For TS and intermediates, this is defined as the diameter of the sphere with the same volume as the van der Waals volume of each species (Section 3.5); for the voids we use the diameter of the largest accessible cavity diameter (Table 1). Such metrics are convenient and easily visualized; yet, they fail to convey a measure of shape and more specifically an accurate representation of the "fit" of these moieties within voids, which ultimately determine the effectiveness of van der Waals interactions and of the concomitant dispersion forces that mediate stabilization by confinement. An alternative method dispenses with geometry altogether and estimates instead the dispersive component of the energies for each organic moiety at all possible locations within a given framework using Lennard-Jones potentials $[69,70]$ between each atom in the organic moiety $\left(\mathrm{X}_{\mathrm{M}}\right)$ and each framework oxygen atom $\left(\mathrm{O}_{\mathrm{Z}}\right)$ :

$$
E_{\mathrm{LJ}}^{X}=\sum_{i}^{o_{Z}} \sum_{h}^{X_{M}} \epsilon\left(\left(\frac{d_{e q}}{d_{i, h}}\right)^{12}-2\left(\frac{d_{e q}}{d_{i, h}}\right)^{6}\right)
$$

These two-atom interaction potentials contain both attractive and repulsive terms and depend on the distance between each $h$ atom in the organic moiety and each $i$ atom in the framework $\left(d_{i, h}\right)$ and on the equilibrium distance for each atom-pair $\left(d_{e q}\right)$, defined here as the sum of their van der Waals radii (O: $0.152 \mathrm{~nm}, \mathrm{H}: 0.120 \mathrm{~nm}, \mathrm{C}: 0.170 \mathrm{~nm})$ [71]. Covalent interactions $\left(d_{i . h}<0.15 \mathrm{~nm}\right)$ are neglected in estimating the $E_{\mathrm{LJ}}^{\mathrm{X}}$ values as defined by Equation 11 . These two- 
atom potentials also depend on a scaling factor, denoted here as $\varepsilon$, which can be determined by benchmarking $E_{\mathrm{LJ}}^{\mathrm{X}}$ values (Eq. 11) for a set of DFT-optimized structures $\left(\varepsilon=1.59 \mathrm{~kJ} \mathrm{~mol}^{-1}\right.$, Section 3.6) against those determined using empirical dispersive energy corrections (DFT-D3) $[33,34]$. D3-methods provide an estimate of the attractive interactions between all of the atoms with each other within a structure $\left(E_{\mathrm{D} 3}^{X+Z}\right)$; therefore, estimates of those interactions between the atoms of the organic moiety and the framework atoms $\left(E_{\mathrm{D} 3}^{X}\right)$, without including the interactions amongst zeolite atoms $\left(E_{\mathrm{D} 3}^{Z}\right)$ and amongst atoms of the organic moiety $\left(E_{\mathrm{D} 3}^{X_{(g)}}\right)$, require that we take the difference of these energies:

$$
E_{\mathrm{D} 3}^{X}=E_{\mathrm{D} 3}^{X+Z}-\left(\mathrm{E}_{\mathrm{D} 3}^{Z}+E_{\mathrm{D} 3}^{X}\right)
$$

Here $E_{\mathrm{D} 3}^{X+Z}$ is the D3-correction for the DFT-optimized structure of the organic moiety $(X)$ within the zeolite void $(Z)$; $\mathrm{E}_{\mathrm{D} 3}^{Z}$ is the D3-correction for the zeolite framework from which the organic moiety has been removed from the DFT-optimized structure of the organic moiety within the zeolite void; $E_{\mathrm{D} 3}^{X_{(g)}}$ is the D3-correction for the gaseous analog of the organic moiety. These D3corrections consider only the attractive dispersive forces between atoms; thus, full DFT simulations are required to generate meaningful structures of the transition states and $\mathrm{H}$-bonded acetone precursors at each distinct T-site within each framework.

The calculation of $E_{\mathrm{LJ}}^{\mathrm{X}}$ requires an algorithm for placing the organic moieties at each accessible location within each framework and the subsequent ensemble-averaging of the energy at each location weighted by the probability of their presence at that location. The DFToptimized structures for the $\mathrm{C}-\mathrm{C}$ bond formation transition state and $\mathrm{H}$-bonded acetone at the T12 site of MFI (VASP, RPBE + D3(BJ)) were placed at each crystallographically distinct T-site 
location in FER, TON, MFI, BEA, and FAU frameworks. Their unit cell parameters and crystal structures were taken from the International Zeolite Association (IZA) [41] (FER: $a=1.9018, b$ $=1.4303, c=0.7541 \mathrm{~nm}$, and $\alpha=\beta=\gamma=90.0^{\circ} ; \mathrm{TON}: a=1.4105, b=1.7842, c=0.5256 \mathrm{~nm}$, and $\alpha=\beta=\gamma=90.0^{\circ}$; BEA: $a=1.2632, b=1.2632, c=2.6186 \mathrm{~nm}$, and $\alpha=\beta=\gamma=90.0^{\circ}$; FAU: $a=2.4345, b=2.4345, c=2.4345 \mathrm{~nm}$, and $\alpha=\beta=\gamma=90.0^{\circ}$ ). The unit cell parameters and crystal structure used for MFI are shown in Section 2.5.

The DFT-derived C-C bond formation transition state consists of an ion-pair (MFI, Al T12 site, VASP, RPBE + D3(BJ)). The charge at each atom was determined using Löwdin population analyses [72] after transforming wavefunctions into localized quasiatomic orbitals (QUAMBO) [73-76]. These charges were then used to calculate the center of charge in the cationic transition state $\left(\bar{\xi}_{\mathrm{TS}}\right)$ and the anionic framework $\left(\bar{\xi}_{\text {anion }}\right)$, each located at their respective $[\mathrm{x}, \mathrm{y}, \mathrm{z}]$ coordinates, given by:

$$
\bar{\xi}_{\mathrm{X}}=\left[\frac{\sum_{i}^{N} C_{i} x_{i}}{N}, \frac{\sum_{i}^{N} C_{i} y_{i}}{N}, \frac{\sum_{i}^{N} C_{i} z_{i}}{N}\right]
$$

where each moiety consists of $N$ atoms, with each $i$ atom having a charge $\left(C_{i}\right)$ and a location $\left[x_{i}\right.$, $\left.y_{i}, z_{i}\right]$. The $\bar{\xi}_{\text {TS }}$ was used as the central node $\left(n_{\text {central }}\right)$ for orienting the transition state at each Tsite location. The $\bar{\xi}_{\text {anion }}$ was located at the Al-atom for the DFT-optimized transition state structure; the distance between the two $\bar{\xi}$ locations ( $n_{\text {central }}$ and Al-atom) was $0.427 \mathrm{~nm}$ at this transition state for the T12 site in MFI. This distance was kept constant at all T-site locations and frameworks because of the large energetic penalties brought forth by the separation of charge.

The DFT-derived structure of H-bonded acetone (MFI, VASP, RPBE + D3(BJ)) maintains the significant covalency of the bond between the proton (considered part of organic moiety) and the framework oxygen $\left(\mathrm{O}_{\mathrm{Z}}\right)$. This $\mathrm{O}_{\mathrm{Z}}-\mathrm{H}$ bond length in DFT-derived structures of $\mathrm{H}$ - 
bonded acetone on MFI is similar at all three accessible O-atoms at the T12 site $(0.110 \pm 0.002$ $\mathrm{nm})$. The proton in the H-bonded acetone was used as $n_{\text {central }}$ and placed at this mean distance from each crystallography distinct $\mathrm{O}_{\mathrm{Z}}$ in FER, TON, MFI, BEA, and FAU frameworks.

The internal angles and atomic distances within the organic moieties (TS and H-bonded acetone) were kept at their DFT-derived values for the T12 site in MFI. These structures were placed at each crystallographically distinct location in each framework using three node locations: (1) the zeolite framework atom $\left(\mathrm{Z}_{\mathrm{Z}}\right.$ : $\mathrm{Al}$-atom $\left(\mathrm{Al}_{\mathrm{Z}}\right)$ or O-atom $\left(\mathrm{O}_{\mathrm{Z}}\right)$ for the transition state or H-bonded acetone, respectively), (2) the central node ( $n_{\text {central }}: \bar{\xi}_{\text {TS }}$ or proton for the transition state or H-bonded acetone, respectively), and (3) the farthest node $\left(n_{\text {farthest }}\right)$ defined as the location of the atom in the organic moiety farthest from $n_{\text {central }}$. The placement of $n_{\text {central }}$ forms a sampling sphere centered at each $Z_{Z}$ with a radius equal to the $n_{\text {central }}-Z_{Z}$ distance described above for the TS and H-bonded acetone and a node spacing of $0.032 \mathrm{~nm}$ [77]; effects of these parameters are the subject of a later study. The organic moiety is then rotated about $n_{\text {central }}$ by varying the angle between the atom of the organic moiety located at $n_{\text {farthest }}\left(\mathrm{X}_{\text {farthest }}\right), n_{\text {central }}$, and $n_{\text {farthest }}\left(\mathrm{X}_{\text {farthest }}-n_{\text {central }}-n_{\text {farthest }}\right.$ angle $)$ by increments of $5^{\circ}\left(0^{\circ}, 5^{\circ}, 10^{\circ}\right.$, etc. $)$ and by varying the angle between the normal vectors to the $X_{\text {farthest }}-n_{\text {central }}-Z_{\text {zeolite }}$ and $n_{\text {farthest }}-n_{\text {central }}-Z_{\text {zeolite }}$ planes by increments of $10^{\circ}\left(0^{\circ}, 10^{\circ}, 20^{\circ}\right.$, etc. $)$; such rotations result in the sampling of 242 unique orientations of the organic moiety for each central node location (angle $-25^{\circ}$ to $25^{\circ}$ and $155^{\circ}$ to $205^{\circ}$, dihedral angle $-50^{\circ}$ to $50^{\circ}$ ). Such methods result in a sampling of $>10^{3}$ orientations of the organic moiety at each $\mathrm{Z}_{\mathrm{Z}}$ atom.

\section{Results and Discussion}




\subsection{Effects of $\mathrm{H}_{2}$ and Pt hydrogenation function on catalyst stability and selectivity}

Mechanistic studies using kinetic, isotopic, and spectroscopic methods require stable catalysts; such stability has remained elusive for condensation reactions on solid acids, even in the presence of a hydrogenation function and $\mathrm{H}_{2}$ [27-30]. Here, we use high $\mathrm{H}_{2} /$ acetone molar ratios (10-100) and low acetone conversions to achieve catalyst stability suitable for kinetic and mechanistic inquiries. These measurements and treatments of condensation rates allow rigorous mechanistic interpretation of condensation rates, albeit with practical hurdles of acetone loss via hydrogenation-dehydration routes (Section S3, SI).

Acetone condensation rates on MFI-3 and BEA-1 decreased with time on stream (Fig. 1), in the absence of a hydrogenation function. First-order deactivation constants ( $k_{\mathrm{d}}$, Eq. 1) decreased as acetone conversion decreased with time. The curvature in the data shown in Figure 1 (MFI-3, BEA-1) suggests that deactivating residues form in sequential reactions of primary condensation products $[78,79]$. Acetone condensation on MFI-3 and BEA-1 led to equilibrated mixtures of mesityl and isomesityl oxides (MO; experimental and theoretical evidence in Section $\mathrm{S} 4, \mathrm{SI})$, and equimolar isobutene and acetic acid mixtures $\left(\mathrm{C}_{4}\right.$ and $\mathrm{C}_{2}$, respectively; Section $\mathrm{S} 5$, SI). $\mathrm{C}_{4} / \mathrm{C}_{6}$ molar ratios increased proportionally with increasing acetone conversion (Fig. 2, MFI3 and BEA-1) indicating that isobutene and acetic acid formed via reactions of primary $\mathrm{C}_{6}$ alkanone products. 

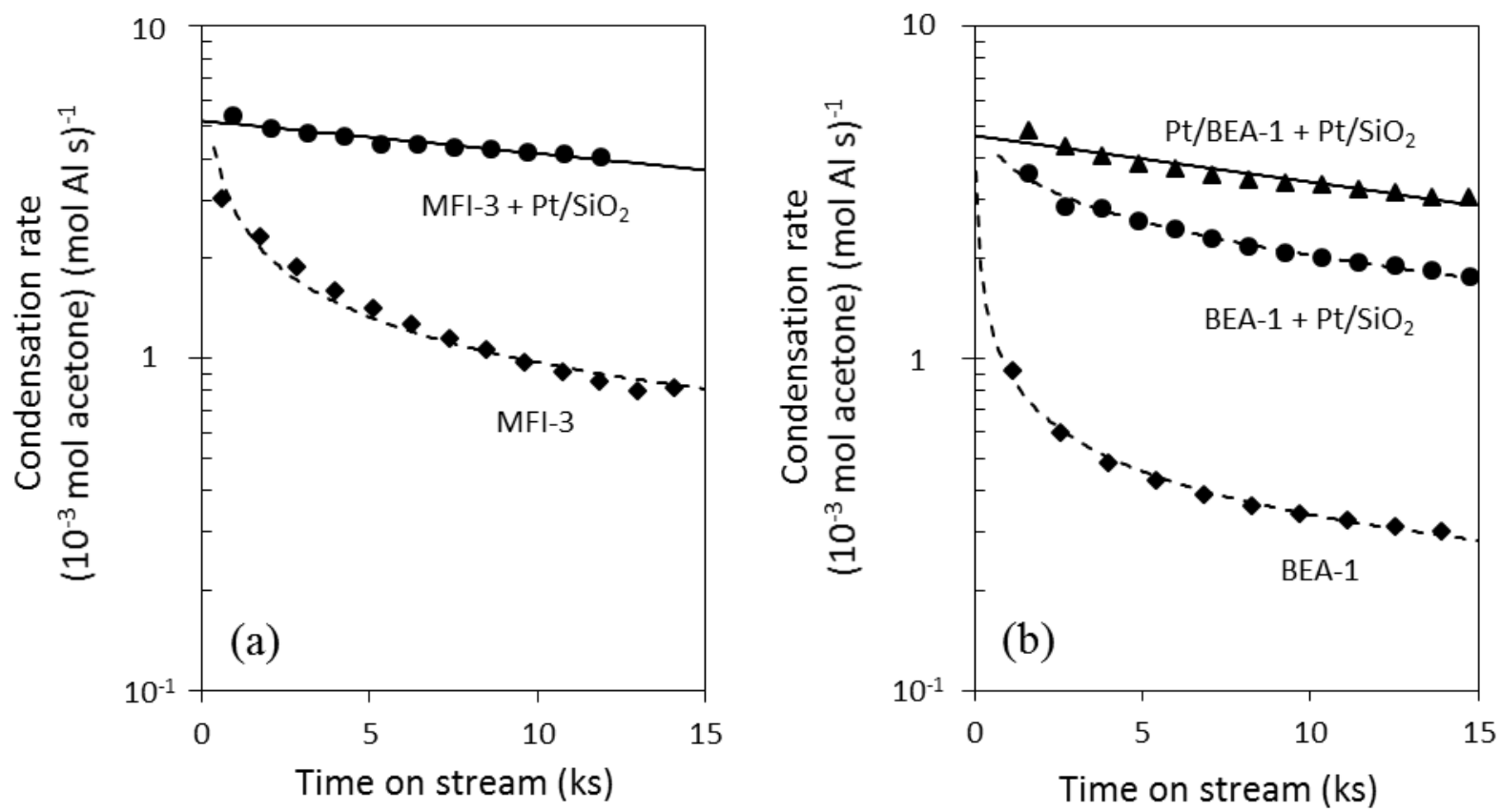

Figure 1: Acetone condensation rate as a function of time on stream on (a) MFI-3 (diamonds) and $\mathrm{MFI}-3+\mathrm{Pt} / \mathrm{SiO}_{2}$ (1\% wt. extracrystalline Pt; circles) and (b) BEA-1 (diamonds), BEA-1 + Pt/SiO 2 (1.3\% wt. extracrystalline $\mathrm{Pt}$; circles), $\mathrm{Pt} / \mathrm{BEA}-1+\mathrm{Pt} / \mathrm{SiO}_{2}(1 \%$ wt. extracrystalline $\mathrm{Pt}$ and $1 \%$ wt. intracrystalline Pt; triangles) (473 K, $2.0 \mathrm{kPa}$ acetone, $27 \mathrm{kPa} \mathrm{H}_{2}$, balance $\left.\mathrm{He}\right)$. Dashed lines represent trends and solid lines are regressed linear fits of the data to the form of Eq. 1.

A Pt function, present as a physical mixture with MFI-3, led to much slower deactivation (Fig. 1a, MFI-3 + Pt/SiO 2 ) and lower $\mathrm{C}_{4} / \mathrm{C}_{6}$ product ratios (Fig. 2a). The very low $\mathrm{C}_{4}$ (isobutane when Pt is present) and acetic acid selectivities obtained with the Pt function present outside MFI crystals indicate that sequential $\beta$-scission events seldom occur before primary products leave zeolite crystals and enter the extracrystalline fluid phase. The hydrogenation of MO products to less reactive methyl isobutyl ketone (MIBK) prevents subsequent condensation and $\beta$-scission of MO or its diacetone alcohol precursors. Initial condensation rates on MFI-3 are not affected by the presence of $\mathrm{Pt} / \mathrm{SiO}_{2}$ (Fig 1a), consistent with kinetically-relevant condensation steps that require only the acid function in MFI. These data also show that acetone conversion to MO and $\mathrm{H}_{2} \mathrm{O}$ is far from equilibrium, because MO conversion to MIBK on the Pt function would have 
otherwise scavenged condensation products resulting in increased measured rates; these conditions are consistent with approach to equilibrium $(\eta)$ values of $1.0 \times 10^{-6}-1.4 \times 10^{-6}$ at the conditions of these experiments:

$$
\eta=\frac{1}{\exp \left(-\frac{G_{M O}+G_{\mathrm{H}_{2} O}-2 G_{A c}}{R T}\right)} \frac{(\mathrm{MO})\left(\mathrm{H}_{2} \mathrm{O}\right)}{(\mathrm{Ac})^{2}}
$$

where the free energy $\left(G_{i}\right)$ of each gaseous species $\left(i=\mathrm{MO}, \mathrm{H}_{2} \mathrm{O}\right.$, and Ac) was estimated using DFT (473 K, VASP, RPBE + D3(BJ)) and $(\mathrm{MO}),\left(\mathrm{H}_{2} \mathrm{O}\right)$, and (Ac) represent the pressures of each of species (units: bar). The initial condensation rate is $5.2 \pm 0.2 \times 10^{-3}(\mathrm{Al} \mathrm{s})^{-1}$ and the $k_{\mathrm{d}}$ value (Eq. 1) is $0.023 \pm 0.006 \mathrm{ks}^{-1}$ on MFI-3 physically mixed with $\mathrm{Pt} / \mathrm{SiO}_{2}(473 \mathrm{~K}, 2.0 \mathrm{kPa}$ acetone, $27 \mathrm{kPa} \mathrm{H}_{2}$ ), where uncertainties represent the $95 \%$ confidence interval of the fitted parameter; similar measurements of condensation rates were used to evaluate plausible elementary steps of the condensation mechanism by measuring the effects of reaction temperature and acetone pressure (Section 3.3).
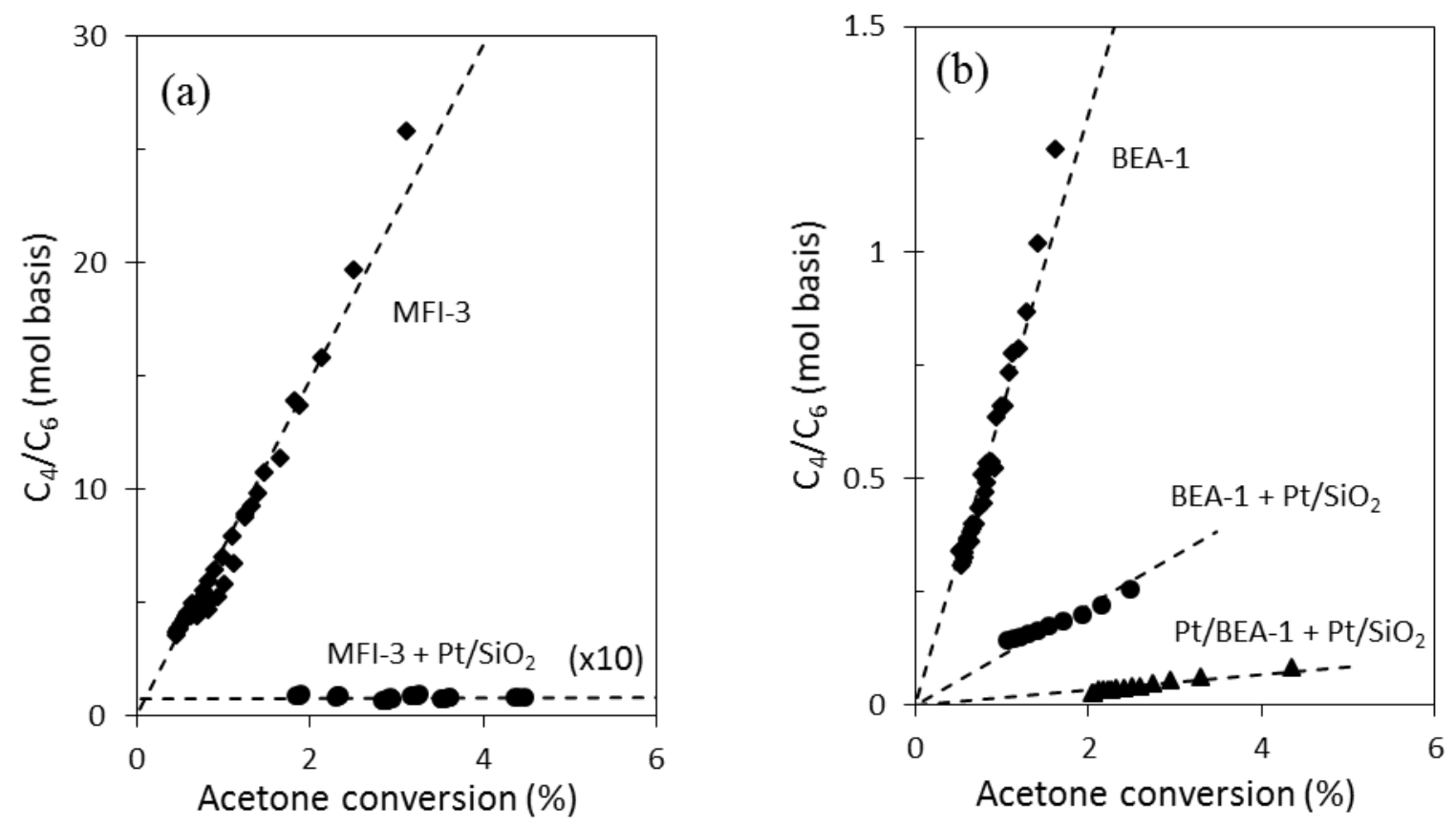


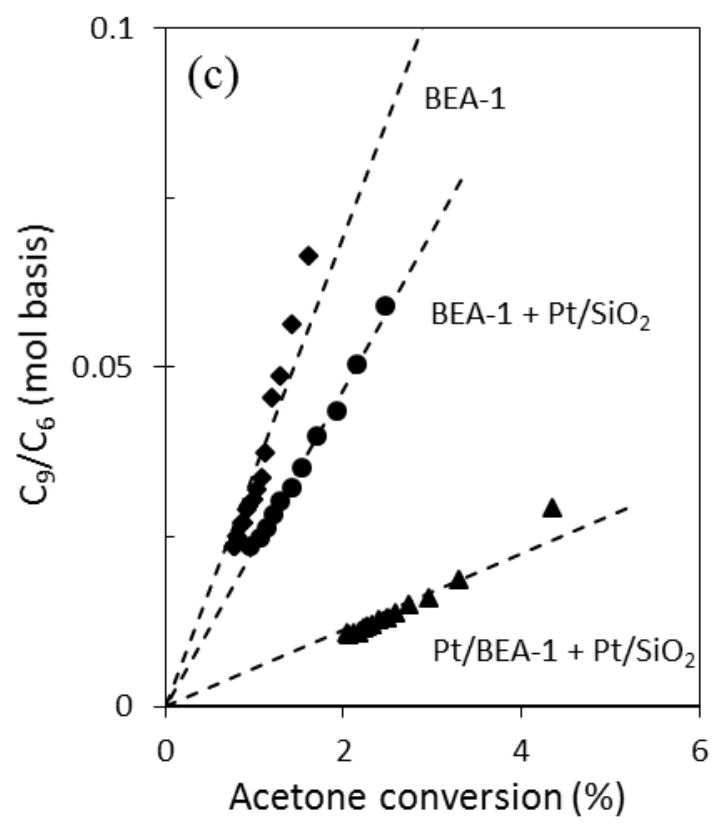

Figure 2: Effect of acetone conversion on $\mathrm{C}_{4} / \mathrm{C}_{6}$ and $\mathrm{C}_{9} / \mathrm{C}_{6}$ product molar ratios on (a) MFI-3 (diamonds) and MFI-3 + Pt/SiO $(1 \%$ wt. extracrystalline Pt; circles) and (b and c) BEA-1 (diamonds), BEA-1 + Pt $/ \mathrm{SiO}_{2}$ (1.3\% wt. extracrystalline Pt; circles), Pt/BEA-1 + $\mathrm{Pt} / \mathrm{SiO}_{2}(1 \%$ wt. intracrystalline Pt and $1 \%$ wt. extracrystalline Pt; triangles) at $473 \mathrm{~K}, 2.0 \mathrm{kPa}$ acetone, $27 \mathrm{kPa} \mathrm{H}$, balance $\mathrm{He} . \mathrm{C}_{4}, \mathrm{C}_{6}$, and $\mathrm{C}_{9}$ denote, respectively, the combined number of moles produced of isobutene and isobutane, $\mathrm{MO}$ and MIBK, and TMB. MIBK and isobutane were only detected when Pt was present. Dashed lines are regressed linear fits of the data through the origin, except $\mathrm{MFI}-3+\mathrm{Pt} / \mathrm{SiO}_{2}$ where the dashed line represents the average $\mathrm{C}_{4} / \mathrm{C}_{6}$ value.

The extracrystalline Pt function was less effective in stabilizing rates on BEA-1 (Fig. 1b, BEA-1 + Pt/SiO 2 ) than on MFI-3 (Fig. 1a, MFI-3 + Pt/SiO 2 ) and also led to larger amounts of $\mathrm{C}_{4}$ and $\mathrm{C}_{9}\left(1,3,5\right.$-trimethylbenzene $(\mathrm{TMB})$ ) products (Fig. $2 \mathrm{~b}$ and $2 \mathrm{c}, \mathrm{BEA}-1+\mathrm{Pt} / \mathrm{SiO}_{2}$ ) than on MFI-3 (Fig. 2a, MFI-3 + Pt/SiO 2 ). These data indicate that extracrystalline $\mathrm{Pt} / \mathrm{SiO}_{2}$ is insufficient to convert all MO molecules into MIBK before subsequent acid-catalyzed reactions, which suggests MO undergoes these acid-catalyzed reactions before leaving the acid domain, an unexpected result for BEA channels $(0.67 \mathrm{~nm}$; Table 1$)$ that are larger than those in MFI $(0.50$ $\mathrm{nm}$; Table 1). This increase in the rates of subsequent reactions of MO is attributed to the increased intrinsic reactivity of active sites within BEA compared to those within MFI due to 
differences in the shape of the confining voids present in the BEA and MFI frameworks, which is discussed in Section 3.6.

Pt clusters, placed within BEA via exchange and subsequent treatments (Section 2.1), led to more stable rates (Fig. 1b, Pt/BEA-1 $+\mathrm{Pt} / \mathrm{SiO}_{2}$ ) and lower $\mathrm{C}_{4}$ and $\mathrm{C}_{9}$ selectivities (Fig. $2 \mathrm{~b}$ and 2c) than for mixtures of $\mathrm{BEA}$ with $\mathrm{Pt} / \mathrm{SiO}_{2}$, but initial condensation rates were unaffected by the presence or location of the Pt function (Fig. 1b). The condensation rates on Pt/BEA-1 + Pt/SiO (473 K, $2.0 \mathrm{kPa}$ acetone, $27 \mathrm{kPa} \mathrm{H}_{2}$ ) decreased with time on stream; the $k_{\mathrm{d}}$ value (Eq. 1) was $0.034 \pm 0.007 \mathrm{ks}^{-1}$ and the initial condensation rate was $4.8 \pm 0.3 \times 10^{-3}(\mathrm{Al} \mathrm{s})^{-1}$.

These initial condensation rates allow, in principle, rigorous assessments of the intrinsic condensation reactivity of protons in aluminosilicates, but require (i) accurate determinations of the number and type of active sites, (ii) rate measurements uncorrupted by intracrystalline gradients, and (iii) a rigorous assessment of the identity and kinetic relevance of the elementary steps that mediate condensation turnovers.

\subsection{Number and type of active sites involved in condensation turnovers}

Al-atoms within silicate frameworks form anionic frameworks with balancing cations that are protons when these solids act as Brønsted acids. Al-atoms present at non-framework locations can act as Lewis acid centers, leading to $\mathrm{H}^{+} / \mathrm{Al}$ ratios smaller than unity (Table 1), indicating that Brønsted and Lewis acid sites may co-exist and catalyze condensation turnovers either as separate sites or by acting in concert to stabilize the relevant transition states, as previously reported [10, 19, 24].

The full suppression of condensation rates by a sterically-hindered non-coordinating base that titrates only protons (2,6-di-tert-butyl pyridine, DTBP) would implicate protons as the only 
acetone condensation active sites. The number of titrants required to suppress rates gives the number of accessible protons during catalysis $[40,80]$. Such titrants can access intracrystalline protons within BEA, FAU, and MCM-41 crystals, but not within medium-pore aluminosilicates (MFI, TON, FER), for which alternate titrants or probes were used, as described below.

Acetone condensation rates decreased monotonically with increasing DTBP uptakes and ultimately became undetectable on Pt/BEA-1 + Pt/SiO 2, BEA-2 + Pt/SiO 2 , and MCM-41 + $\mathrm{Pt} / \mathrm{SiO}_{2}$ (Fig. 3), indicating that only protons catalyze condensation turnovers without detectable contributions from any Lewis acid centers present. These data cannot rule out concerted routes requiring both types of acid sites, such as those involving $\mathrm{C}-\mathrm{C}$ bond formation between alkenols at non-framework $\mathrm{Al}$ sites and protonated acetone at Brønsted acid sites [19, 24]; these routes are excluded by the similar turnover rates (per proton) on MFI catalysts with 16.6-168.3 Si/Al ratios (Section 3.3).

DTBP titration and the amount of $\mathrm{NH}_{3}$ evolved upon heating $\mathrm{NH}_{4}$-exchanged samples led to similar proton counts in large-pore zeolites (BEA-1, BEA-2, FAU; Table 1). The latter method was used for medium-pore zeolites (TON, MFI; Table 1), because DTBP cannot readily diffuse through TON and MFI channels. Pyridine was used for FER samples because large cage-like structures in FER $\left(0.70 \mathrm{~nm}\right.$ diameter, [35]) would be accessible to $\mathrm{NH}_{3}$ but not to acetone $(0.50$ nm kinetic diameter, [46]) or pyridine. Such cages can only be accessed through small windows $(0.33 \mathrm{~nm}$ diameter, [47]), and as a result only the protons in the channels $(0.53 \mathrm{~nm}$ diameter, [35]) are accessible to acetone, making pyridine uptakes the appropriate measure of the number of protons responsible for FER reactivity (FER; Table 1). 


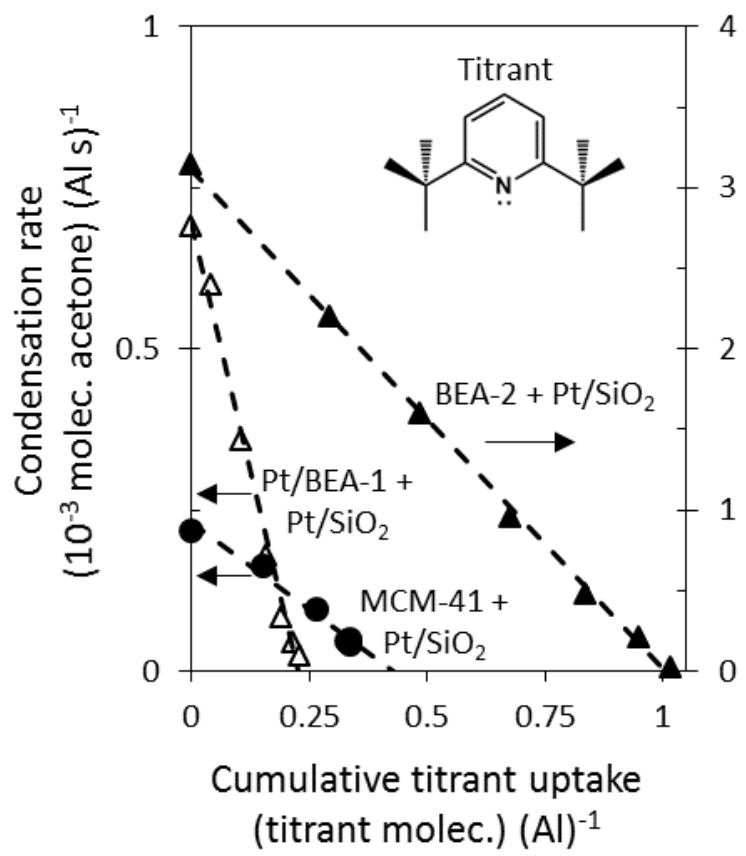

Figure 3: Acetone condensation rates as a function of cumulative 2,6-di-tert-butyl pyridine uptakes on $\mathrm{Pt} / \mathrm{BEA}-1+\mathrm{Pt} / \mathrm{SiO}_{2}$ (1\% wt. intracrystalline $\mathrm{Pt}$ and $1 \%$ wt. extracrystalline Pt; open triangles), BEA-2 $+\mathrm{Pt} / \mathrm{SiO}_{2}$ (1.3\% wt. extracrystalline Pt; closed triangles), and $\mathrm{MCM}-41+\mathrm{Pt} / \mathrm{SiO}_{2}(0.66 \%$ wt. extracrystalline Pt; closed circles) $(473 \mathrm{~K}, 0.3 \mathrm{kPa}$ acetone, $27 \mathrm{kPa} \mathrm{H}$, and 0.6-1.2 $\mathrm{Pa}$ 2,6-di-tert-butyl pyridine). Dashed lines are regressed linear fits of the data.

\subsection{Mechanistic interpretations of the effects of temperature and acetone concentration on condensation turnover rates}

The effects of acetone pressure on condensation turnover rates (per proton) were measured on Pt-containing samples of MFI (MFI-1, MFI-2, MFI-3, MFI-4), BEA (BEA-1, BEA2), FAU, MCM-41, FER, and TON aluminosilicates; all samples showed $k_{\mathrm{d}}$ values (Eq. 1) below $0.05 \mathrm{ks}^{-1}$. Figure 4 shows these rate data as a function of acetone pressure on MFI-3, BEA-1, and MCM-41 (0.1-5.0 kPa acetone, $473 \mathrm{~K})$. Similar first-order kinetic dependences were observed on all other samples (Fig. S.4, S6, SI; 0.1-4 kPa acetone). Condensation turnover rates (v) were proportional to acetone pressure $(\mathrm{Ac})$ : 


$$
v \equiv \frac{r}{\left[\mathrm{H}^{+}\right]}=k_{e f f}(\mathrm{Ac})
$$

with effective first-order rate constants $\left(k_{e f f}\right)$ given by the slopes of the rate data in Figure 4 (and Fig. S.4, S6, SI).

These $k_{\text {eff }}$ values were independent of proton density (0.4-3.5 $\mathrm{H}^{+} /$unit cell; Fig. 5), Si/Al ratio (MFI: 17-168, BEA: 12-43; Table 1), and $\mathrm{H}^{+} / \mathrm{Al}$ ratio (MFI: 0.65-1.03, BEA: 0.22-1.04; Table 1) on MFI and BEA (Fig. 5). These data indicate the absence of intracrystal acetone gradients, which would become more severe with increasing proton density, leading to a concomitant decrease in rates. These MFI and BEA samples contain different ratios of protons and non-framework $\mathrm{Al}$ sites and yet yield similar turnover rates (per proton), suggesting that neither Lewis acid sites nor Lewis-Brønsted site pairs mediate condensation turnovers. Such turnovers occur only at Brønsted acid sites. Also, the local void environment around protons in these MFI and BEA samples appears to be independent of Al content because confinement effects, dictated by the local geometric topology of the framework, would have led to differences in reactivity, as shown in Sections 3.5 and 3.6. 


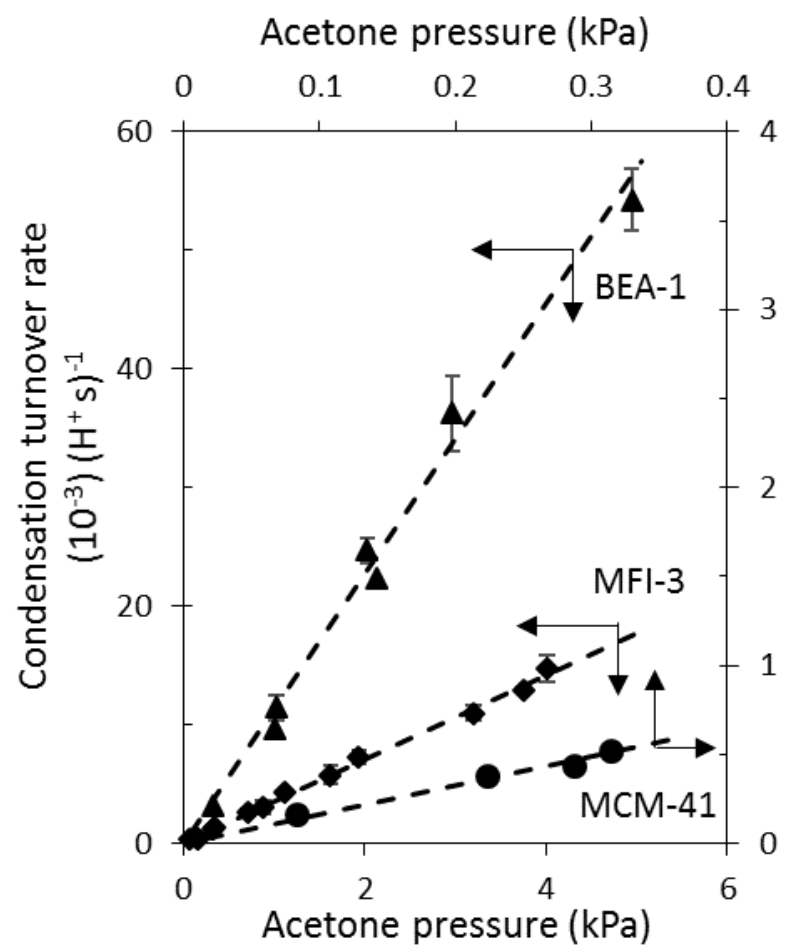

Figure 4: Condensation turnover rate as a function of acetone pressure on Pt/BEA-1 + $\mathrm{Pt} / \mathrm{SiO}_{2}$ (1\% wt. intracrystalline $\mathrm{Pt}$ and $1 \%$ wt. extracrystalline $\mathrm{Pt}$; triangles), $\mathrm{MFI}-3+\mathrm{Pt} / \mathrm{SiO}_{2}$ ( $1 \%$ wt. extracrystalline $\mathrm{Pt}$; diamonds), and MCM-41 + Pt/SiO 2 (0.66\% wt. extracrystalline $\mathrm{Pt}$; circles) $\left(473 \mathrm{~K}, 27 \mathrm{kPa} \mathrm{H}_{2}\right)$. Dashed lines are regressed fits of rate data to the form of Eq. 15 . Bars represent $95 \%$ confidence intervals of the extrapolation of rate data to zero conversion.

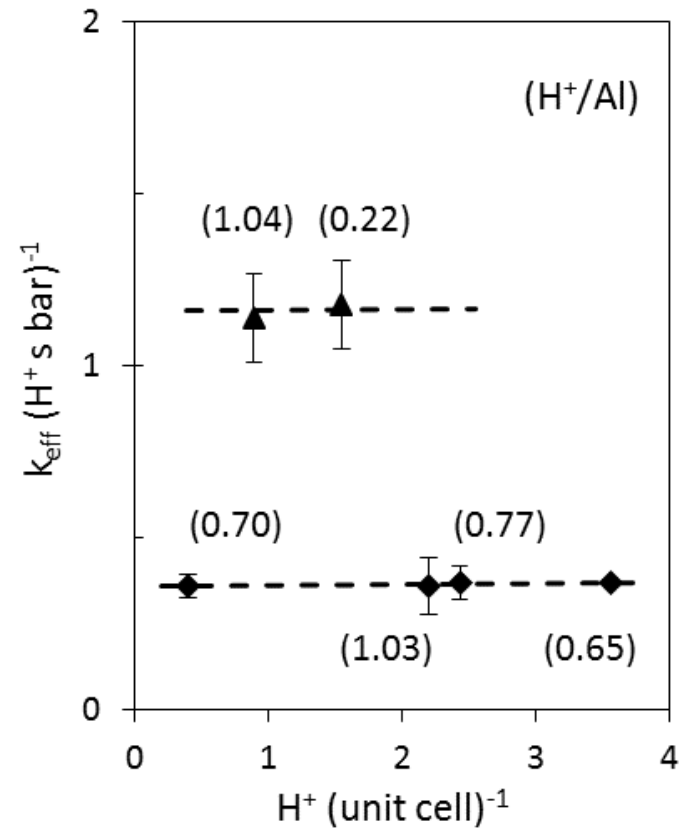

Figure 5: Effective first-order rate constants as a function of proton density (per unit cell) on Ptcontaining samples of MFI (MFI-1, MFI-2, MFI-3, MFI-4; diamonds) and BEA (BEA-1, BEA-2; triangles) samples (473 K, 0.1-5 $\mathrm{kPa}$ acetone, $27 \mathrm{kPa}$ $\mathrm{H}_{2}$ ). $\mathrm{H}^{+} / \mathrm{Al}$ ratios for all samples are shown in parentheses next to their corresponding data point. Bars represent $95 \%$ confidence intervals of the regressed linear fits of rate data to the form of Eq. 15.

These condensation rate dependencies are consistent with two plausible mechanistic assumptions in the context of the elementary steps in Scheme 3. One route involves kineticallyrelevant monomolecular $\alpha-\mathrm{C}-\mathrm{H}$ activation of acetone on essentially uncovered proton sites $\left(K_{A c}(\mathrm{Ac})<<1\right.$, Eq. 16). These pathways are similar to those proposed based on DFT treatments, which determine the formation of $\mathrm{C}_{3}$-alkenols via tautomerization of acetone as the sole kinetically-relevant step on microporous aluminosilicates (FER, MFI, MCM-22) [81]. The resulting rate equation is: 


$$
v=\frac{k_{\text {taut }}(\mathrm{Ac})}{1+K_{A c}(\mathrm{Ac})} \approx k_{\text {taut }}(\mathrm{Ac})
$$

with $k_{\text {taut }}$ as the rate constant for acetone tautomerization (Step 3.2, Scheme 3) and $K_{A c}$ as the equilibrium adsorption constant for H-bonded acetone (Step 3.1, Scheme 3). A similar functional form of the rate equation is obtained if $\mathrm{C}-\mathrm{C}$ bonds form in the kinetically-relevant step via reactions of gaseous acetone with $\mathrm{H}$-bonded acetone present at saturation coverages $\left(K_{A c}(\mathrm{Ac})>>\right.$ 1, Eq. 17):

$$
v=\frac{k_{C C} K_{t a u t} K_{A c}(\mathrm{Ac})^{2}}{1+K_{A c}(\mathrm{Ac})} \approx k_{C C} K_{\text {taut }}(\mathrm{Ac})
$$

where $k_{C C}$ is the rate constant for C-C formation (Step 3.3, Scheme 3) and $K_{\text {taut }}$ is the acetone tautomerization equilibrium constant (Step 3.2, Scheme 3).

Scheme 3: Proposed sequence of elementary steps for acetone condensation to $\mathrm{C}_{6}$-products on $\mathrm{Br}$ acid sites

Step Rate constant*<smiles>CC(=O)[Hg]</smiles>
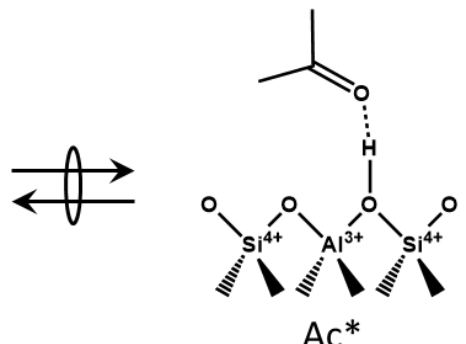

$K_{\text {Ac }}$

$$
\mathrm{AC}^{*}
$$
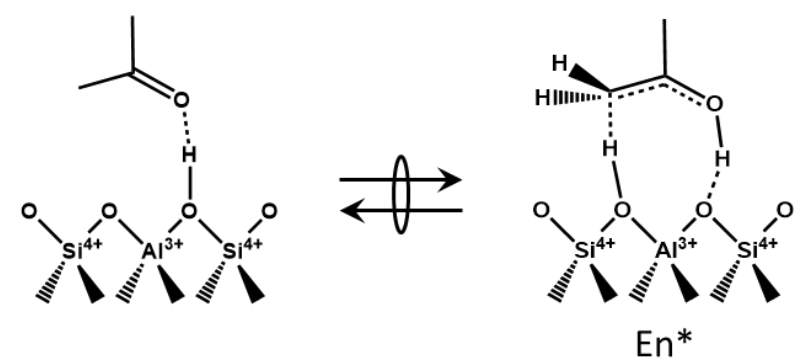

$K_{\text {taut }}$ 

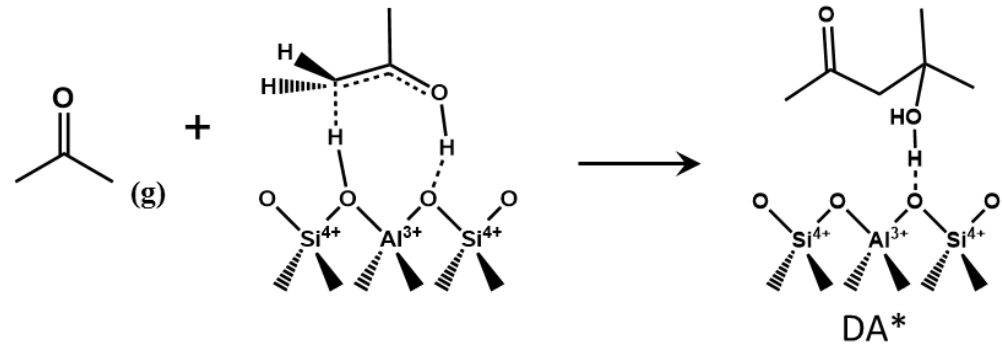

$k_{C C}$

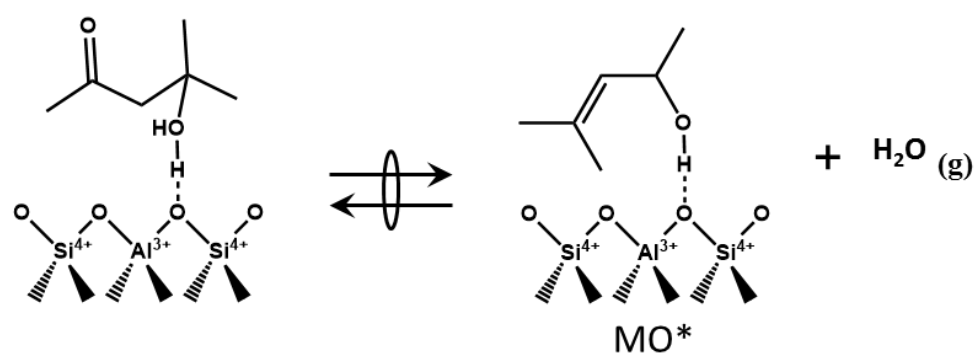

$K_{\text {dehyd }}$<smiles>CC(=O)CC(C)(C)OB1O[C@](C)(O)[C@@]2(C)C[C@](C)(O)O[C@@]12C</smiles>
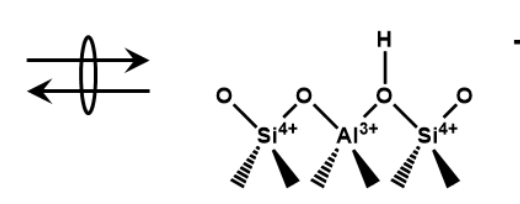<smiles>CC(=O)CC(C)(O)[Hg]</smiles>

$\left(K_{\mathrm{DA}}\right)^{-1}$

diacetone alcohol
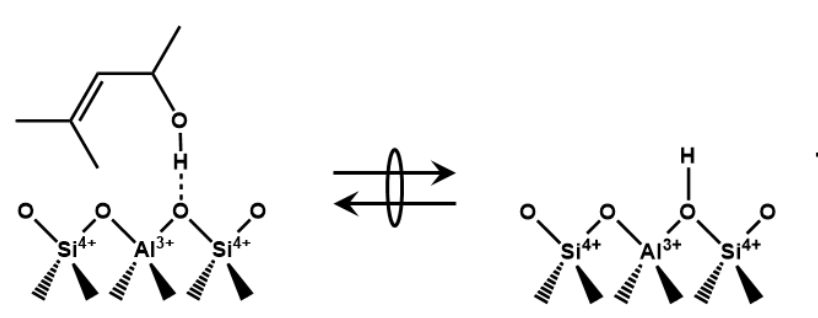<smiles>CC(=O)C=C(C)[Hg]</smiles>

$\left(K_{\mathrm{MO}}\right)^{-1}$

mesityl oxide
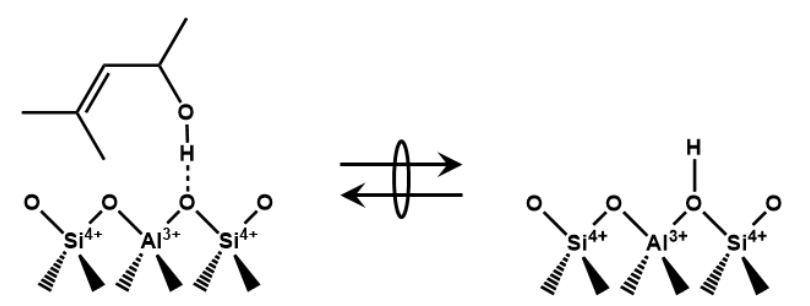<smiles>CC(=O)CC(C)=O</smiles>

$\left(K_{\mathrm{IMO}}\right)^{-1}$ isomesityl oxide

$* k_{x}$ and $K_{x}$ denote kinetic constants for forward steps and equilibrium constants, respectively. Quasi-equilibrated steps are indicated by an open circle over the double arrows. 
The identity of the most abundant adsorbed species during acetone condensation represents the arbiter of the contributions of these two routes (Eqs. 16 and 17). H-bonded acetone species are reported on MFI-3 during acetone condensation from infrared spectra (473 K, 0-0.04 $\mathrm{kPa}$ acetone). MFI-3 shows an $\mathrm{O}-\mathrm{H}$ stretch at $3600 \mathrm{~cm}^{-1}$ (Fig. 6, inset) before contact with acetone (473 K, $100 \mathrm{~cm}^{3} \mathrm{~g}^{-1} \mathrm{~s}^{-1} \mathrm{He}$ flow), consistent with DFT-derived frequencies for acidic OH groups (3440-3660 $\mathrm{cm}^{-1}$, Table 2, VASP, RPBE + D3(BJ) and vdW-DF2) and with previously reported spectra $[82,83]$. Contact with acetone at reaction temperatures $(473 \mathrm{~K}, 0.04 \mathrm{kPa}$ acetone, $100 \mathrm{~cm}^{3} \mathrm{~g}^{-1} \mathrm{~s}^{-1} \mathrm{He}$ flow) led to the disappearance of the acidic $\mathrm{O}-\mathrm{H}$ band and to the concurrent emergence of a new band at $2360 \mathrm{~cm}^{-1}\left(2110-2650 \mathrm{~cm}^{-1}\right.$; Fig. 6). This band is assigned to perturbations of $\mathrm{O}-\mathrm{H}$ groups by $\mathrm{H}$-bonding with acetone based on DFT-derived frequencies of H-bonded acetone at O-H groups in MFI (2260-2455 $\mathrm{cm}^{-1}$, Table 2, VASP, vdWDF2) and on previous studies [84, 85]. Bands for $\mathrm{C}-\mathrm{H}$ stretches in the $\mathrm{CH}_{3}$ group of gaseous [86] and H-bonded acetone species also emerged (2800-3000 $\mathrm{cm}^{-1}$; Fig. 6). Theoretical treatments show that these C-H stretches in $\mathrm{H}-$ bonded acetone occur at $2950-3120 \mathrm{~cm}^{-1}$ (Table 2, VASP, vdW-DF2 and RPBE + D3(BJ)), consistent with measured spectral features during acetone condensation catalysis. 


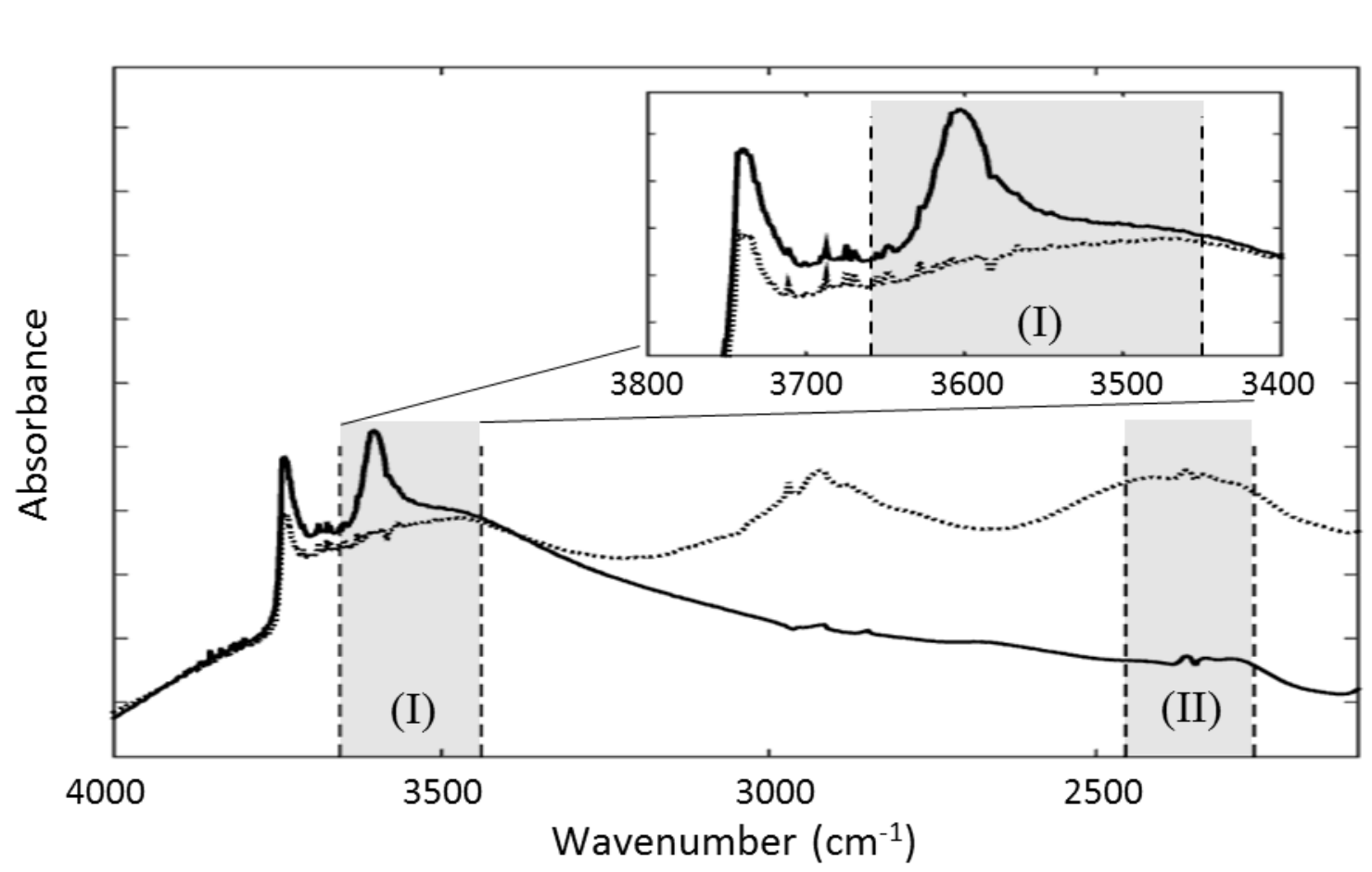

Figure 6: Infrared spectra of MFI-3 before contact with acetone (473 K, $100 \mathrm{~cm}^{3} \mathrm{~g}^{-1} \mathrm{~s}^{-1} \mathrm{He}$; solid line) and during acetone condensation $\left(473 \mathrm{~K}, 0.04 \mathrm{kPa}\right.$ acetone, $100 \mathrm{~cm}^{3} \mathrm{~g}^{-1} \mathrm{~s}^{-1} \mathrm{He}$; dashed line). The shaded regions denote ranges of DFT-calculated frequencies for acidic $\mathrm{O}-\mathrm{H}$ stretches when (I) unperturbed (3440-3660 $\mathrm{cm}^{-1}$; Table 2) and (II) H-bonding with acetone (2260-2455 $\mathrm{cm}^{-1}$; Table 2, VASP, vdW-DF2, PAW5).

These infrared spectra, their theoretical interpretation, and DFT-derived adsorption free energies $\left(\left\langle\Delta G_{H-A c}\right\rangle\right)$ ensemble-averaged at the three acetone-accessible O-atoms $\left(\mathrm{O}_{\mathrm{Z}}\right)$ present at the T12 site in MFI (-80 and $-79 \mathrm{~kJ} \mathrm{~mol}^{-1}$ using RPBE + D3(BJ) and vdW-DF2 functionals, respectively; Table 2) indicate the prevalence of proton sites nearly saturated with H-bonded acetone at all conditions $(0.04-5 \mathrm{kPa}$ acetone, 463-483 K), consistent with the mechanistic interpretation leading to Equation $17\left(K_{A c}(\mathrm{Ac})>>1\right)$. DFT-derived structures (Table 2) show that the proton is not transferred to the bound acetone, which is instead stabilized by H-bonding. The $\mathrm{O}_{\mathrm{Z}}-\mathrm{H}^{+}$bonds $(0.110 \mathrm{~nm} ; \mathrm{RPBE}+\mathrm{D} 3(\mathrm{BJ})$, Table 2$)$ are shorter than the $\mathrm{O}_{\mathrm{Ac}}-\mathrm{H}^{+}$bonds $(0.136 \mathrm{~nm}$; $\mathrm{RPBE}+\mathrm{D} 3(\mathrm{BJ})$, Table 2) and the $\mathrm{O}_{\mathrm{Z}}-\mathrm{H}^{+}-\mathrm{O}_{\mathrm{Ac}}$ bond angle is almost $180^{\circ}\left(174^{\circ}\right.$, Table 2); these geometries are those expected for H-bonding instead of protonated acetone species [87]. 
Table 2: DFT estimates for bond distances (nm), bond angles (degrees), bond stretching frequencies $\left(\mathrm{cm}^{-1}\right)$, and Gibbs free energies $\left(\mathrm{kJ} \mathrm{mol}^{-1}\right)$ for the bare proton and $\mathrm{H}$-bonded acetone species at each $\mathrm{O}$ atom vicinal to the T12 Al-site of the MFI framework

DFT Functional:

RPBE + D3(BJ)

vdW-DF2

$\left(\mathrm{O}_{\mathrm{Z}}\right)^{\mathrm{a}}$ :

$\begin{array}{lll}\mathrm{O} 20 & \mathrm{O} 11 & \mathrm{O} 24\end{array}$

$\mathrm{O} 12^{\mathrm{b}}$

$\mathrm{O} 20$

$\mathrm{O} 11$

$\mathrm{O} 24$

$\mathrm{O} 12^{\mathrm{b}}$

\section{bare proton}

$\mathrm{O}_{\mathrm{Z}}-\mathrm{H}^{+}$

$v\left(\mathrm{O}_{\mathrm{Z}}-\mathrm{H}^{+}\right)$

0.098

$P_{H^{+}-O_{Z}}{ }^{\mathrm{c}}$

$3613 \quad 3650 \quad 3570$

0.098

0.098

0.097

0.098

0.099

$\begin{array}{lll}0.14 & 0.66 \quad 0.05\end{array}$

0.15

3629

3658

3594

3439

0.16

0.74

0.03

0.07

\section{H-bonded acetone}

\begin{tabular}{|c|c|c|c|c|c|c|}
\hline $\mathrm{O}_{\mathrm{Z}}-\mathrm{H}^{+}$ & 0.110 & 0.110 & 0.111 & 0.105 & 0.104 & 0.105 \\
\hline $\mathrm{O}_{\mathrm{Ac}}-\mathrm{H}^{+}$ & 0.136 & 0.136 & 0.137 & 0.153 & 0.154 & 0.152 \\
\hline $\mathrm{O}_{\mathrm{Z}}-\mathrm{O}_{\mathrm{Ac}}$ & 0.246 & 0.248 & 0.247 & 0.256 & 0.258 & 0.256 \\
\hline $\mathrm{C}=\mathrm{O}_{\mathrm{Ac}}$ & 0.125 & 0.125 & 0.125 & 0.125 & 0.125 & 0.125 \\
\hline$\angle \mathrm{O}_{\mathrm{Z}}-\mathrm{H}^{+}-\mathrm{O}_{\mathrm{Ac}}$ & 171.2 & 175.0 & 173.3 & 166.0 & 171.2 & 170.7 \\
\hline$\angle \mathrm{C}=\mathrm{O}_{\mathrm{Ac}}-\mathrm{H}^{+}$ & 121.0 & 121.2 & 121.2 & 129.5 & 128.6 & 127.5 \\
\hline$v\left(\mathrm{O}_{\mathrm{Z}^{-}} \mathrm{H}^{+}\right)$ & 1843 & 2020 & 1820 & 2378 & 2455 & 2259 \\
\hline \multirow[t]{6}{*}{$v\left(\mathrm{C}_{\mathrm{Ac}}-\mathrm{H}_{\mathrm{Ac}}\right)$} & 3120 & 3119 & 3116 & 3067 & 3076 & 3068 \\
\hline & 3109 & 3107 & 3113 & 3052 & 3065 & 3061 \\
\hline & 3065 & 3052 & 3068 & 3015 & 3003 & 3016 \\
\hline & 3056 & 3039 & 3047 & 3007 & 2993 & 2996 \\
\hline & 2998 & 2990 & 2991 & 2971 & 2964 & 2964 \\
\hline & 2986 & 2981 & 2985 & 2962 & 2956 & 2949 \\
\hline$\left(\Delta G_{A C *}\right)^{\mathrm{d}}$ & -78 & -83 & -80 & -82 & -75 & -90 \\
\hline$\left\langle\Delta G_{A C *}\right\rangle^{\mathrm{e}}$ & & \multirow{2}{*}{\multicolumn{2}{|c|}{$\begin{array}{l}-82 \\
1.00\end{array}$}} & & \multirow{2}{*}{\multicolumn{2}{|c|}{$\begin{array}{c}-79 \\
-\quad 1.00\end{array}$}} \\
\hline$\theta_{A c}{ }^{\mathrm{f}}$ & & & & & & \\
\hline
\end{tabular}

${ }^{\mathrm{a}}$ Framework $\mathrm{O}$-atoms $\left(\mathrm{O}_{\mathrm{Z}}\right)$ numbered according to convention [61] (Scheme 2)

${ }^{\mathrm{b}} \mathrm{H}^{+}-\mathrm{O} 12$ is inaccessible to acetone

${ }^{\mathrm{c}}$ Probability of a proton at each $\mathrm{O}_{\mathrm{Z}}$ based on Gibbs free energy, Eq. 7 (473 K)

${ }^{\mathrm{d}}$ Free energy of acetone binding, Eq. 5 (473 K, standard pressure of acetone)

${ }^{\mathrm{e}}$ Ensemble-averaged free energy, Eq. 6. (473 K, standard pressure of acetone)

${ }^{\mathrm{f}}$ Acetone coverage, Eq. 10 (473 K, 4 × 10 $0^{-4}$ bar acetone, similar conditions as in Fig. 6)

The proposals that lead to Equations 16 and 17 also include kinetically-relevant transition states that differ in the involvement of $\mathrm{H}$-atoms in the bonds being formed or cleaved. The tautomerization transition state (Eq. 16) mediates $\alpha-\mathrm{C}-\mathrm{H}$ bond cleavage and the formation of 
$\mathrm{O}_{\mathrm{Ac}}-\mathrm{H}$ bonds (Step 3.2, Scheme 3). In contrast, the $\mathrm{C}-\mathrm{C}$ bond formation transition state (Eq. 17) does not involve the formation or cleavage of bonds containing $\mathrm{H}$-atoms. As a result, these mechanistic proposals would lead to different H/D kinetic isotope effects (KIE; Eq. 2).

Measured rates of acetone- $\mathrm{d}_{0} / \mathrm{H}_{2}$ and acetone- $\mathrm{d}_{6} / \mathrm{D}_{2}$ condensation on MFI-3 were nearly identical $(0.98 \pm 0.03 \mathrm{KIE}, 473 \mathrm{~K}$; SI, S7, Fig. S.5) and thus inconsistent with the mechanistic interpretations leading to Equation 16, which requires proton transfer from an $\mathrm{O}_{\mathrm{Z}}$ in the framework to $\mathrm{O}_{\mathrm{Ac}}$ in acetone and from the $\alpha-\mathrm{C}$ in acetone to another $\mathrm{O}_{\mathrm{Z}}$ atom (Step 3.2, Scheme 3). The DFT-derived KIE value for this tautomerization TS structure is 2.1 (473 K, Al T12 site, MFI, VASP, RPBE + D3(BJ)). The kinetically-relevant step involved in the sequence leading to Equation 17 is mediated by a bimolecular TS that resembles a $\mathrm{C}_{3}$-alkenol, in quasi-equilibrium with H-bonded acetone, which incipiently forms a C-C bond with a protonated acetone (Step 3.3, Scheme 3). Such a TS does not involve the formation or cleavage of $\mathrm{C}-\mathrm{H}$ or $\mathrm{O}-\mathrm{H}$ bonds and would exhibit small thermodynamic isotope effects. The DFT-derived KIE values (1.1 KIE; 473 K, T12 site, MFI, RPBE + D3(BJ)) agree with measured values (0.98 $\pm 0.03 \mathrm{KIE} ; 473 \mathrm{~K}, \mathrm{MFI}-3)$. These kinetic, spectroscopic, and isotopic data demonstrate that $\mathrm{C}-\mathrm{C}$ bonds form via kineticallyrelevant steps involving reactions of gaseous acetone with $\mathrm{H}$-bonded acetone, the latter present at near-saturation coverages in equilibrium with gaseous acetone.

We conclude that $k_{\text {eff }}$ in Equation 15 represents the kinetic and thermodynamic parameters in Equation 17 and that the first-order measured rates at near saturation coverages of H-bonded acetone:

$$
v=\left(k_{C C} K_{\text {taut }}\right)(\mathrm{Ac})
$$


reflect the free energy differences that determine $k_{C C}$ and $K_{\text {taut }}$, the kinetic and thermodynamic constants for $\mathrm{C}-\mathrm{C}$ bond formation from the $\mathrm{C}_{3}$-alkenol and gaseous acetone and for tautomerization from gaseous acetone, respectively (Steps 3.2 and 3.3, Scheme 3). These constants are related to the free energy barrier of Step 3.3 in Scheme 3 (Eq. 8) and to the free energy difference between a $\mathrm{H}$-bonded acetone and a $\mathrm{H}$-bonded $\mathrm{C}_{3}$-akenol using (Eq. 9):

$$
k_{C C} K_{\text {taut }}=\frac{k_{B} T}{h} \exp \left(-\frac{G_{C C}^{\ddagger}-\left(G_{E n *}+G_{A C}\right)}{k_{B} T}\right) \exp \left(-\frac{G_{E n *}-G_{A C *}}{k_{B} T}\right)
$$

Here, $G_{i}$ represents the free energy of each species $\left(i=C C, E n^{*}, A c^{*}, A c\right.$ refers to the C-C bond formation transition state, the $\mathrm{H}$-bonded $\mathrm{C}_{3}$-alkenol, the $\mathrm{H}$-bonded acetone, and the gaseous acetone). This equation can be simplified by combining terms to give:

$$
k_{C C} K_{\text {taut }}=\frac{k_{B} T}{h} \exp \left(-\frac{G_{C C}^{\ddagger}-\left(G_{A C *}+G_{A C}\right)}{k_{B} T}\right)
$$

Equation 20 shows that $k_{\text {eff }}$ (Eq. 15; $k_{C C} K_{\text {taut }}$ ) reflects differences in Gibbs free energy between the C-C bond formation transition state $\left(G_{C C}^{\ddagger}\right)$ and its two relevant precursors, a H-bonded $\left(G_{A C *}\right)$ and a gaseous acetone $\left(G_{A c}\right)$. The measured free energy barrier $\left(\Delta G^{\ddagger}\right)$ on MFI-3 is $122 \pm 9 \mathrm{~kJ}$ $\mathrm{mol}^{-1}\left(473 \mathrm{~K}, \mathrm{MFI}-3+\mathrm{Pt} / \mathrm{SiO}_{2}\right.$; Fig. 4) and its enthalpy $\left(\Delta H^{\ddagger}\right)$ and entropy $\left(\Delta S^{\ddagger}\right)$ components are $20 \pm 6 \mathrm{~kJ} \mathrm{~mol}^{-1}$ and $-213 \pm 10 \mathrm{~J}(\mathrm{~mol} \mathrm{~K})^{-1}$, respectively, which were determined by regression of measured rates (463-483 K, MFI-3 + Pt/SiO 2 , Fig. 7) to the form of:

$$
k_{C C} K_{\text {taut }}=\frac{k_{B} T}{h} \exp \left(-\frac{\Delta H^{\ddagger}-T \Delta S^{\ddagger}}{k_{B} T}\right)
$$

These data are compared to DFT-derived enthalpies and free energies for the species and elementary steps (Scheme 3) in Section 3.4. 


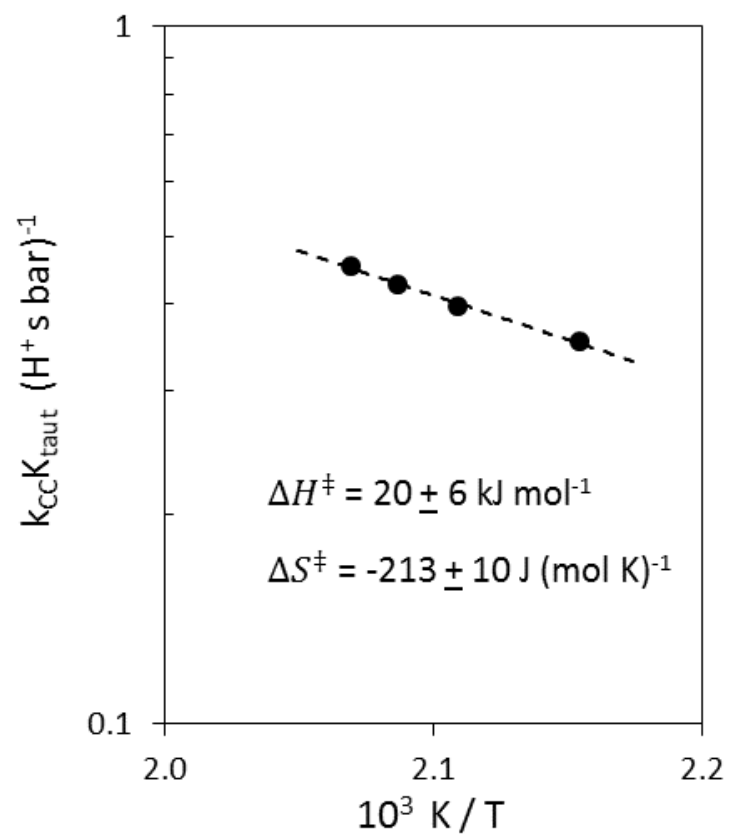

Figure 7: First-order condensation rate constant as a function of reaction temperature on MFI-3 + $\mathrm{Pt} / \mathrm{SiO}_{2}$ (1\% wt. extracrystalline Pt; 463-483 K, 0.3-1 kPa acetone, $27 \mathrm{kPa} \mathrm{H}$ ). Dashed line represents regressed fit to the form of Eq. 21.

\subsection{Theoretical assessment of intermediates and transition states involved in acetone condensation}

The reaction coordinate for $\mathrm{C}-\mathrm{C}$ bond formation in Figure 8 involves the elongation of the $\alpha-\mathrm{C}-\mathrm{H}$ bond in $\mathrm{H}$-bonded acetone as it interacts with a vicinal $\mathrm{O}_{\mathrm{Z}}$ atom to form a bound alkenol-like species through TS1 (Fig. 9). Such alkenol-type species have been inferred from ${ }^{1} \mathrm{H}-$ NMR spectra that show rapid exchange between bound acetone- $\mathrm{d}_{6}$ and $\mathrm{OH}$ groups and also between bound ${ }^{13} \mathrm{C}$-2-acetone and OD groups in MFI [88]. The DFT-derived free energies in Figure 8 show that the activation barriers for the formation of alkenols $\left(\Delta \mathrm{G}=60 \mathrm{~kJ} \mathrm{~mol}^{-1}\right.$ and $\Delta \mathrm{H}=84 \mathrm{~kJ} \mathrm{~mol}^{-1}$, Fig. 8) differ significantly from measured acetone condensation barriers $(\Delta \mathrm{G}=$ $122 \pm 9 \mathrm{~kJ} \mathrm{~mol}^{-1}$ and $\Delta \mathrm{H}=20 \pm 6 \mathrm{~kJ} \mathrm{~mol}^{-1}$ ). The reaction that re-forms H-bonded acetone from $\mathrm{C}_{3}$-alkenols is essentially barrierless $\left(\Delta \mathrm{G}=2 \mathrm{~kJ} \mathrm{~mol}^{-1}\right.$, Fig. 8), consistent with previous studies [81]. This reverse barrier is also much smaller than that for the reaction of bound alkenols with 
acetone to form the C-C bond TS (TS2; $\Delta \mathrm{G}=60 \mathrm{~kJ} \mathrm{~mol}^{-1}$, Fig. 8), indicating that the alkenol formation step is quasi-equilibrated with H-bonded acetone (Step 3.2, Scheme 3) and with gaseous acetone. Therefore, $\mathrm{C}_{3}$-alkenol species represent a kinetically-irrelevant 'ledge' along the climb from the acetone reactants to the kinetically-relevant transition state (TS2, Fig. 8) and $k_{\text {eff }}$ reflects, in fact, the free energy difference between TS2 and two acetone molecules, one Hbonded and one in the gas phase.

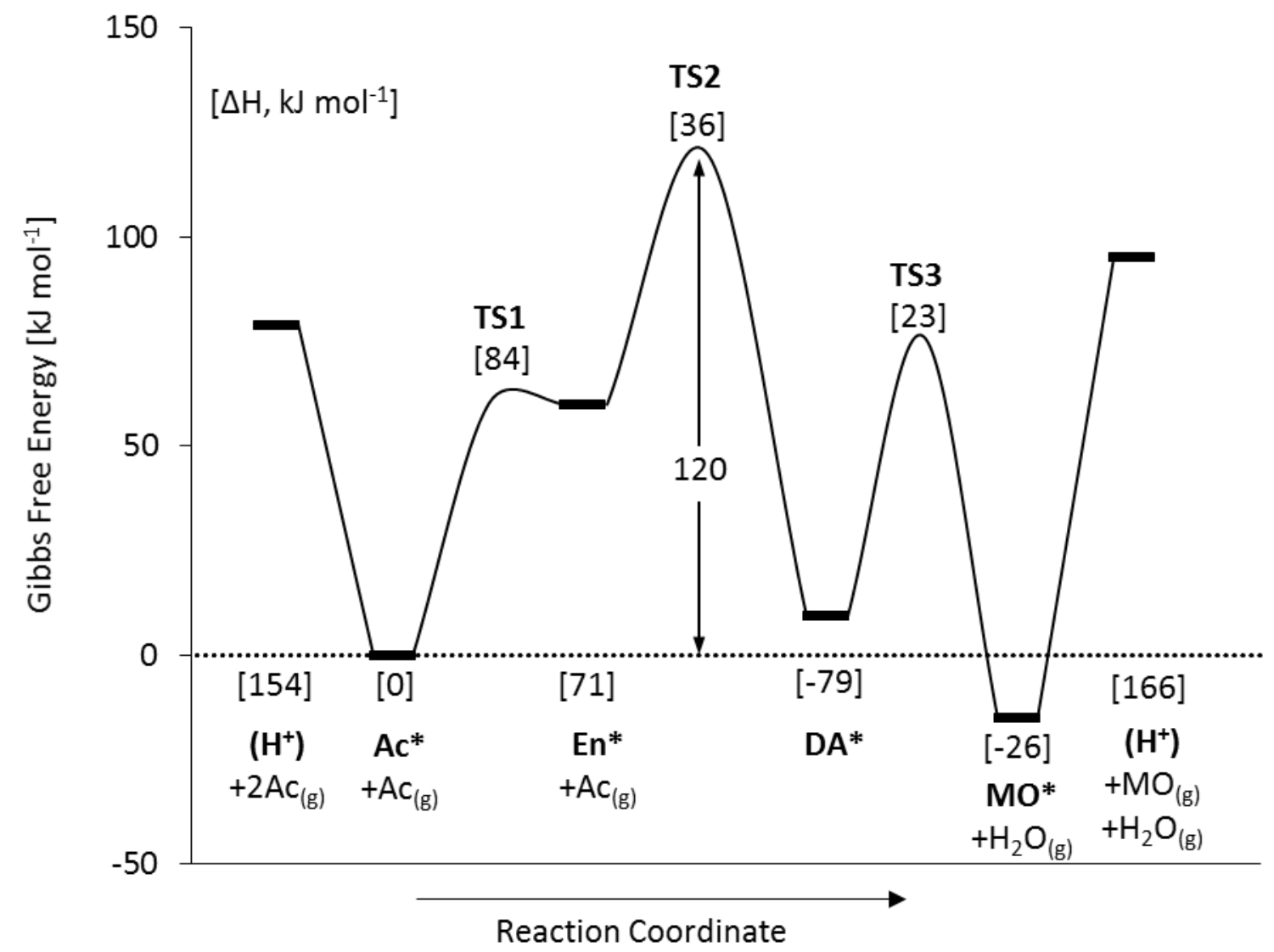

Figure 8: Gibbs free energy diagram for acetone condensation on MFI at $473 \mathrm{~K}$ and standard pressure (1 bar) of gaseous species calculated by DFT, VASP, RPBE+D3(BJ) (methods described in Section 2.5). Enthalpy of each state, referenced to H-bonded acetone and gaseous acetone, shown in square brackets. Labels reflect the notation defined and used in Scheme 3.

The formation of the C-C bond (Step 3.3, Scheme 3) is mediated by a bimolecular transition state (TS2, Fig. 9) that resembles a protonated acetone incipiently linked to a $\mathrm{C}_{3^{-}}$ 
alkenol. This transition state is an ion-pair, which requires that the framework accepts a significant negative charge (0.83 e , QUAMBO analysis; Section 2.6). The incipiently-formed C$\mathrm{C}$ bond at TS2 is much longer $(0.257 \mathrm{~nm})$ than in the protonated diacetone alcohol that forms in this step $(0.154 \mathrm{~nm})$, indicating that the $\mathrm{C}-\mathrm{C}$ bond is not yet fully formed. The DFT-derived free energy and enthalpy barriers to form TS2 from H-bonded acetone and gaseous acetone are 120 $\mathrm{kJ} \mathrm{mol}^{-1}$ and $36 \mathrm{~kJ} \mathrm{~mol}^{-1}$ (Fig. 8), respectively, which are in reasonable agreement with measured barriers $\left(\Delta \mathrm{G}=122 \pm 9 \mathrm{~kJ} \mathrm{~mol}^{-1}\right.$ and $\left.\Delta \mathrm{H}=20 \pm 6 \mathrm{~kJ} \mathrm{~mol}^{-1}\right)$.

The dehydration of diacetone alcohol to MO (Step 3.6, Scheme 3) involves proton transfer via an E1-type elimination, the deprotonation of the MO carbocation, mediated by a transition state resembling a protonated $\mathrm{MO}$ and a neutral $\mathrm{H}_{2} \mathrm{O}$ molecule (TS3, Fig. 9). The C-H bond in the $\mathrm{CH}_{3}$-group of the protonated $\mathrm{MO}$ is then cleaved to form isomesityl oxide and $\left[\mathrm{H}_{3} \mathrm{O}\right]^{+}$. The calculated free energy and enthalpy barriers required to form this TS3 from its relevant precursors are $76 \mathrm{~kJ} \mathrm{~mol}^{-1}$ and $23 \mathrm{~kJ} \mathrm{~mol}^{-1}$, respectively; this free energy barrier is smaller (by $44 \mathrm{~kJ} \mathrm{~mol}^{-1}$; Fig. 8) than that required to form for TS2. Consequently, the reverse barrier for diacetone alcohol to re-form its precursors is higher than for its forward dehydration barrier, leading to the rapid dehydration of the diacetone alcohol intermediates to mesityl oxide and isomesityl oxide (MO; Steps 3.5-3.7, Scheme 3). 

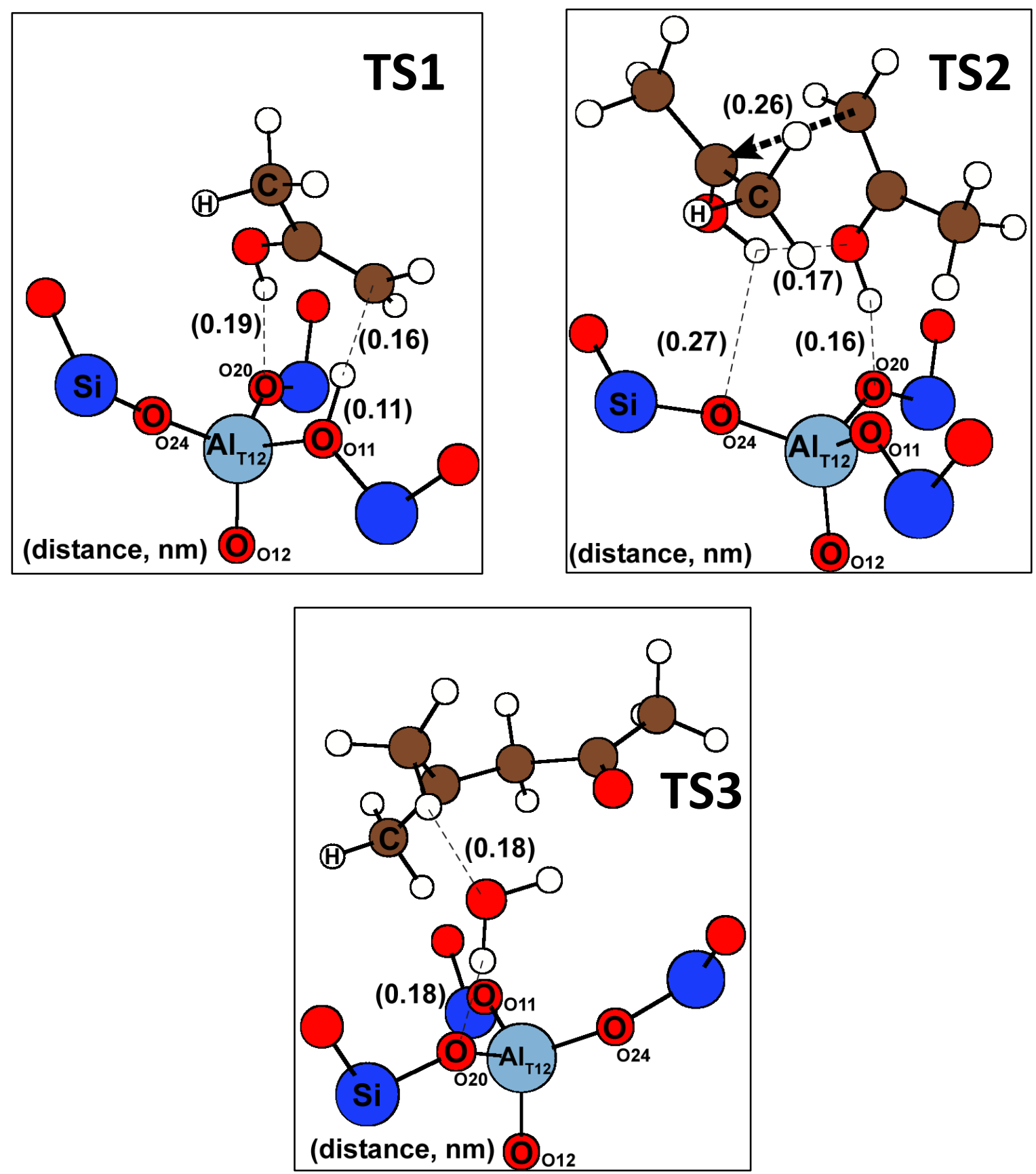

Figure 9: Structures of transition states that mediate enol formation (TS1), C-C bond formation (TS2), and diacetone alcohol dehydration (TS3) on MFI (Al T12 site, VASP, RPBE + D3(BJ)). Transition state labelling corresponds to the notation in Figure 8; atom labelling corresponds to that in Scheme 2. Dashed lines represent interactions between molecules and the zeolite framework, and distances between atoms involved in these interactions are provided in parentheses $(\mathrm{nm})$. The dashed arrow shown on TS2 represents the C-C bond being formed. 


\subsection{Consequences of the local void environment for acetone condensation turnover rates}

These kinetic, isotopic, and infrared data reported above, taken together with their mechanistic confirmation through theoretical treatments, show that the free energy difference between TS2 and its relevant H-bonded acetone and gaseous acetone precursors represents the barrier that determines condensation turnover rates (Eq. 20). These mechanistic interpretations allow an assessment of the effects of the voids in stabilizing the confined TS2 and H-bonded acetone species. The relative stabilization of these two confined species via van der Waals contacts would, in turn, determine the intrinsic catalyst reactivity of protons within a given void environment; we expect that turnover rates will therefore depend sensitively on the size and shape of these two species (H-bonded acetone and TS2) and of the framework voids.

A starting point in defining size and shape for the organic moieties is based on geometry, specifically on the van der Waals radii of their constitutive atoms. The volumes $\left(V_{v d W}\right)$ of each moiety can be defined using an ellipsoid:

$$
V_{v d W}=\frac{4}{3} \pi\left(\frac{d_{x}}{2}+\frac{d_{y}}{2}+\frac{d_{z}}{2}\right)^{3}
$$

Here $d_{i}(i=x, y, z)$ are the largest distance across each organic moiety in three orthogonal directions (Fig. 10). A characteristic diameter $\left(d_{C}\right)$ :

$$
d_{\mathrm{C}}=2\left(\frac{3}{4 \pi} V_{v d W}\right)^{1 / 3}
$$

is then defined as that of a sphere of volume $V_{v d W}$, reducing the size of the organic moiety to a single dimension. The DFT-derived $V_{v d W}$ and $d_{C}$ values (MFI, Al T12 site, VASP, RPBE + D3(BJ)) are $0.182 \mathrm{~nm}^{3}$ and $0.704 \mathrm{~nm}$ for TS2 and $0.085 \mathrm{~nm}^{3}$ and $0.545 \mathrm{~nm}$ for H-bonded acetone (Fig. 10). Their different sizes bring significant consequences for the extent to which TS2 and H- 
bonded acetone are stabilized by van der Waals interactions as the confining voids approach these molecular dimensions.
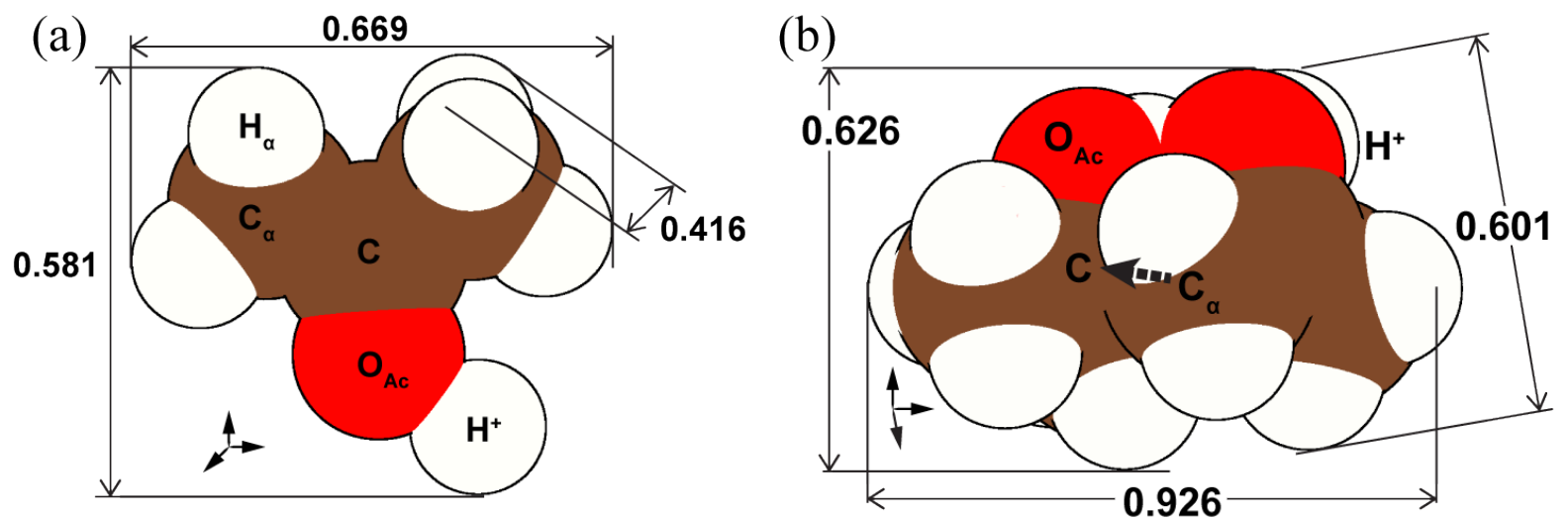

Figure 10: DFT-estimated size of (a) H-bonded acetone and (b) the C-C bond formation transition state (TS2, Fig. 9). Distances are provided in nm (MFI, Al T12 site, VASP, RPBE + D3(BJ)) and atom labelling corresponds to that in Scheme 2. Atom sizes reflect their respective van der Waals radii [71]. The dashed arrow in (b) denotes the $\mathrm{C}-\mathrm{C}$ bond being formed.

The measured condensation turnover rates (per accessible proton) were proportional to acetone pressure on all aluminosilicates (Fig. 4: MFI, BEA, MCM-41; Fig. S.4, SI: FER, TON, FAU), suggesting that kinetically-relevant steps and the chemical interpretation of the rate constants $\left(k_{C C} K_{\text {taut }}\right.$; Eq. 18) are similar on all aluminosilicates. These rate constants are determined by free energy barriers (Eq. 20 and Fig. 8) that are sensitive to the nature of the active protons, reflecting the ability of the local coordination environment to accept charge in the conjugate anion (acid strength) and to allow van der Waals contacts with the framework atoms. The reactivity depends on acid strength because TS2 and H-bonded acetone differ significantly in charge, thus causing the preferential stabilization of the ion-pair TS2 structure $\left(0.83 \mathrm{e}^{-}\right.$; QUAMBO analysis) over the nearly neutral H-boned acetone (0.20 e-; QUAMBO analysis) as the conjugate anions become more stable in stronger acids. The acid strength, however, is similar among aluminosilicates of very diverse frameworks [13], which provide the very different 
confining environments that lead to the diverse reactivity of aluminosilicates in condensation reactions (Fig. 11) and in catalytic reactions in general [12].

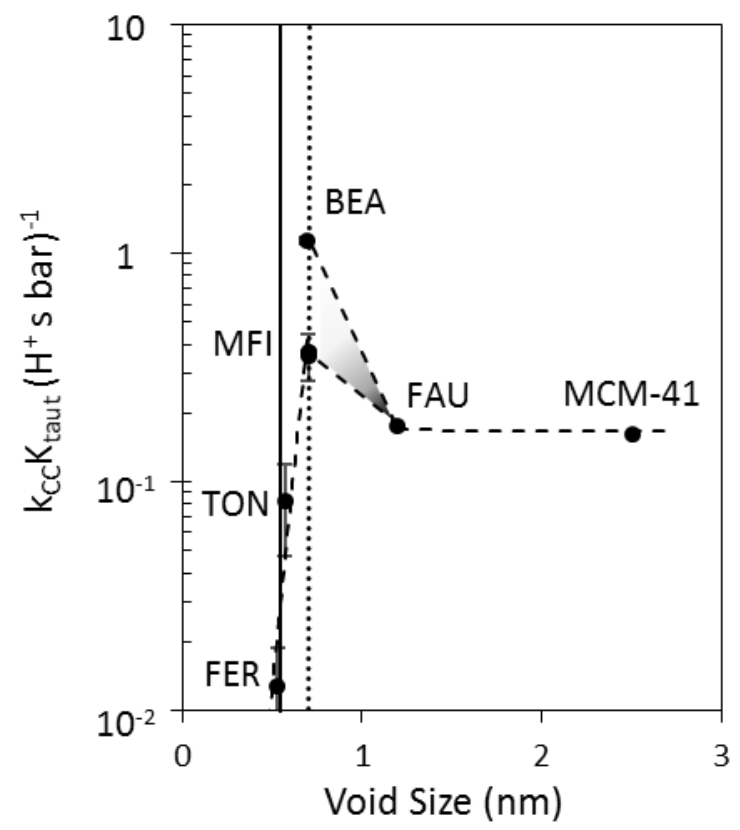

Figure 11: First-order acetone condensation rate constants $\left(473 \mathrm{~K}, 0.1-5 \mathrm{kPa}\right.$ acetone, $\left.27 \mathrm{kPa} \mathrm{H}_{2}\right)$ as a function of aluminosilicate void size (largest accessible cavity diameter; Table 1). All samples contain $\mathrm{Pt}$ (amount and location of Pt provided in Fig. 4 for MFI, BEA, MCM-41 and in SI, Fig. S.4 for FER, TON, FAU). Bars represent $95 \%$ confidence intervals of the regressed linear fits of rate data to the form of Eq. 18. Vertical lines represent the DFT-estimated diameters $\left(d_{C}\right.$, Eq. 23; Fig. 10) of H-bonded acetone (solid) and TS2 (dotted). Dashed lines connect data points.

The values of $k_{C C} K_{\text {taut }}$ obtained from the effects of acetone pressure on condensation rates (Figs. 4 and S.4, SI) are similar on MCM-41 and FAU (Fig. 11), indicating that their large voids stabilize the smaller TS2 and H-bonded acetone structures only slightly. These $k_{C C} K_{\text {taut }}$ values increased as the confining voids approach the size of the TS2 structures (BEA, MFI; Fig. 11) because of its preferential stabilization over the smaller H-bonded acetone precursors (Fig. 10) and the concomitant decrease in the relevant free energy barriers (Eq. 17). The values of $k_{C C} K_{\text {taut }}$ decreased sharply as the voids became even smaller (TON, FER; Fig. 11) because they 
preferentially stabilize H-bonded acetone over larger TS2 structures (as discussed in detail in Section 3.6).

The $k_{C C} K_{\text {taut }}$ kinetic constants on aluminosilicates differing in void environment, taken together with DFT-derived dimensions of kinetically-relevant species and transition states (Fig. 11), show that void size provides an adequate, albeit heuristic, metric of "size matching" and of the consequences of confinement for free energy barriers. Yet, $k_{C C} K_{\text {taut }}$ values for voids of similar size in BEA and MFI differ by a factor of three (Fig. 11), indicative of the incomplete nature of such metrics in describing van der Waals contacts, at least in part, because they ignore the implication of the shape and diversity of the local geometry, even within a given framework type (MFI, FER; Table 1). For instance, MFI and FER contain larger voids connected by smaller apertures, as evident from the differences between their respective largest cavity and pore limiting diameters (Table 1). More complete descriptors of confinement require that the shape of the voids and of the relevant organic moieties be rigorously described and that reactivity descriptors reflect the diverse local void environments that exist even within a given framework structure.

\subsection{Energy metrics as more complete descriptors of stabilization by confinement within voids of molecular dimensions}

A more accurate description of van der Waals interactions requires the enumeration of all distances between framework atoms and each atom in the confined organic moieties at each location within a given framework and for all conformations of the confined moeities [43]. Here, a thermochemical cycle (Scheme 4) is first considered in order to describe the apparent energy barrier for the overall condensation reaction $\left(\Delta E^{T S 2}\right.$; corrected for zero-point energy and thermal contributions) as: 


$$
\Delta E^{T S 2}=\left(-E_{\mathrm{int}}^{A c *}\right)+\Delta E_{\mathrm{prot}}^{T S 2}+E_{\mathrm{int}}^{T S 2}
$$

where $E_{\text {int }}^{A C *}$ and $E_{\text {int }}^{T S 2}$ represent the interaction energies of H-bonded acetone and TS2 with the conjugate anion and the surrounding framework, respectively. $\Delta E_{\text {prot }}^{T S 2}$ denotes the energy recovered when the gaseous analog of a H-bonded acetone reacts with a gaseous acetone to form the TS2 structure as a gaseous species (Scheme 4). This dissection of the activation energy into hypothetical, but rigorous and convenient, components leverages the path-independent properties of thermodynamic state functions that underpin transition state theory [89, 90]. It also allows the isolation of the contributions from interactions $\left(E_{\mathrm{int}}^{X} ; X=A c^{*}\right.$ or $\left.T S 2\right)$ between each organic moiety and each proton that resides within the confining voids.

These $E_{\text {int }}^{X}$ values can be each dissected into two components:

$$
E_{\mathrm{int}}^{X}=E_{\mathrm{ES}}^{X}+E_{\mathrm{vdW}}^{X}
$$

where $E_{\mathrm{ES}}^{X}$ is the electrostatic interaction energy, introduced by the separation of charge between the cationic and anionic components at TS2 and H-bonded acetone [91], and $E_{\mathrm{vdW}}^{X}$ accounts for the dispersive interactions between the organic moiety and the framework.

Scheme 4: A thermochemical cycle depicting the activation barrier to form TS2 from H-bonded acetone and gaseous acetone $\left(\Delta E^{T S 2}\right)$ as the reverse of the interaction energy of $\mathrm{H}$-bonded acetone with the conjugate anion $\left(-E_{\mathrm{int}}^{A C *}\right)$, the energy required to form a gaseous TS2 cation from gaseous acetone and gaseous H-bonded acetone cation $\left(\Delta E_{\text {prot }}^{T S 2}\right)$, and the interaction energy of TS2 cation with the conjugate anion $\left(E_{\text {int }}^{T S 2}\right){ }^{a}$ 


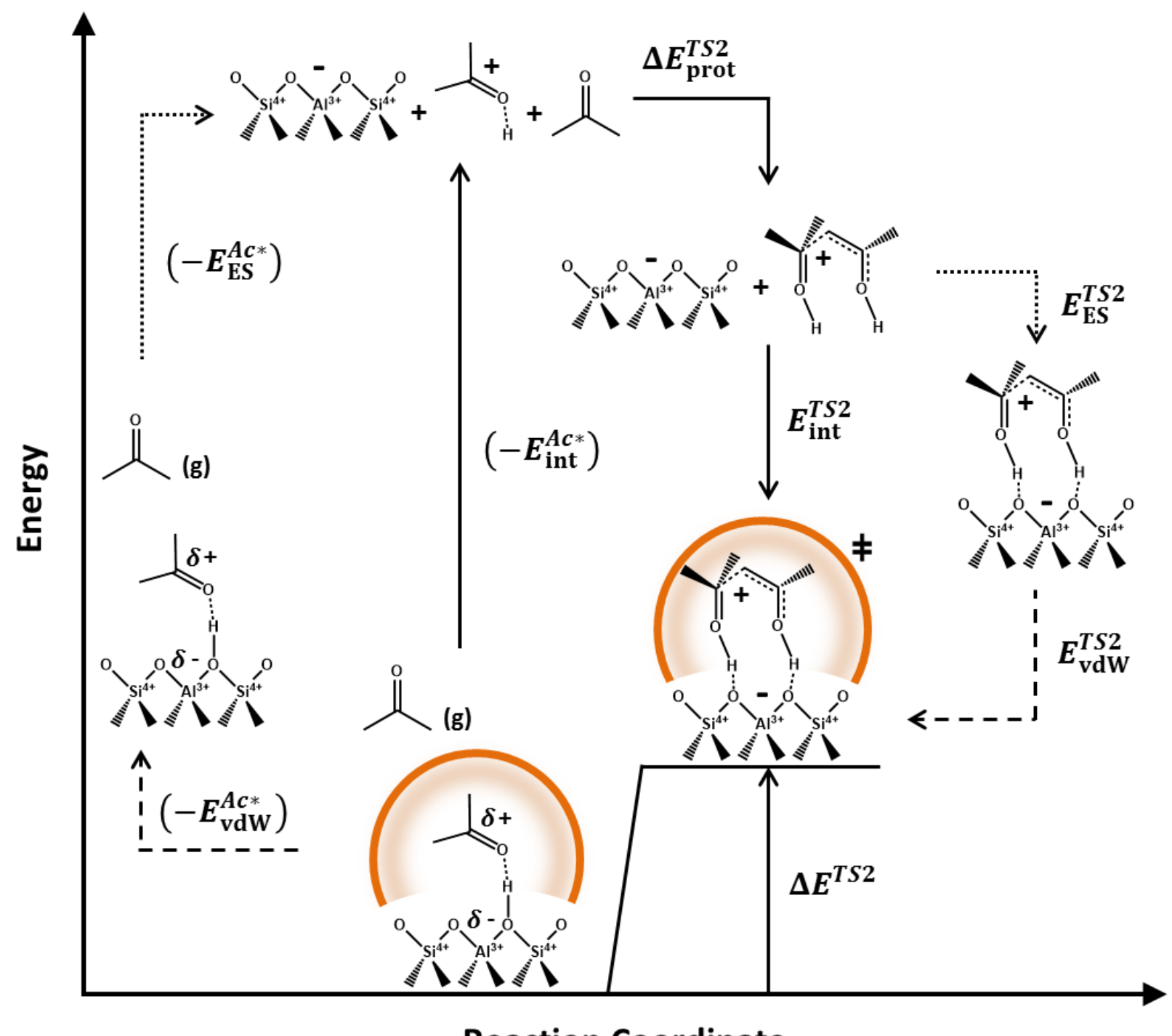

\section{Reaction Coordinate}

${ }^{a}$ Total interation energies (solid arrows) are separated into electrostatic (ES; dotted arrows) and van der Waals (vdW; dashed arrows) interaction components.

The consequences of confinement for activation barriers and reactivity were examined using this thermochemical construct (Scheme 4). The $\Delta E_{\text {prot }}^{T S 2}$ term represents catalystindependent properties of gaseous species. The $E_{\mathrm{ES}}^{X}$ values for TS2 and H-bonded acetone depend on acid strength, a catalyst property that is similar among aluminosilicates with different 
crystalline frameworks [13]. As a result, the $E_{\mathrm{vdW}}^{X}$ values for TS2 and H-bonded acetone $\left(\Delta E_{\mathrm{vdW}}\right)$ are the only terms in Equation 24 that influence stabilization by the confining voids:

$$
\Delta E_{\mathrm{vdW}}=E_{\mathrm{vdW}}^{T S 2}-E_{\mathrm{vdW}}^{H-A c}
$$

These $\Delta E_{\mathrm{vdW}}$ values differ among the diverse T-site locations within each framework structure as a result of differences in their local environments.

The ensemble-averaged $\Delta E_{\mathrm{vdW}}$ values $\left(\left\langle\Delta E_{\mathrm{vdW}}\right\rangle\right)$ are determined by the exponential averaging of van der Waals stabilization energies at each distinct Al T-site location in a given framework:

$$
\left\langle\Delta E_{\mathrm{vdW}}\right\rangle=-k_{B} T \ln \left(\sum_{i}^{N_{\mathrm{T}-\mathrm{site}}} \exp \left(-\frac{\Delta E_{\mathrm{vdW}, i}}{k_{B} T}\right) \mathrm{P}_{\mathrm{T}-\text { site }, i}\right)
$$

where $N_{\text {T-site }}$ is the number of crystallographically-distinct T-site locations in the framework; $\Delta E_{\mathrm{vdW}, i}$ represents the difference in van der Waals interaction energy between the transition state and the precursors at each $\mathrm{T}$-site, $i$; and $\mathrm{P}_{\mathrm{T} \text {-site, } i}$ represents the probability that an Al-atom, and thus a proton, is located at a given T-site. These ensemble-averages allow rigorous comparisons between measured rate constants and DFT-derived barriers.

The $E_{\mathrm{vdW}}^{X}$ term reflects interactions among the atoms in the organic moieties and the framework atoms. These interaction energies can be quantified using empirical dispersive energy corrections (DFT-D3) [33, 34], as described in Section 2.6. These DFT-D3 methods require DFT-optimized structures of the organic moiety at each distinct T-site within each framework, an infeasible approach at present, which we avoid by locating DFT-derived structures of TS2 and H-bonded acetone obtained at the T12 site in MFI (Fig. 10) at each of the T-site locations within MFI and all other frameworks (FER, TON, MFI, BEA, FAU) using protocols described in 
Section 2.6. $E_{\mathrm{vdW}}^{X}$ values were determined from the Lennard-Jones interactions $[69,70]$ between each atom in the organic moiety $\left(\mathrm{X}_{\mathrm{M}}\right)$ and each framework $\mathrm{O}_{\mathrm{Z}}$ atom (Eq. 11).

Comparisons of $E_{\mathrm{D} 3}^{X}$ values and $E_{\mathrm{Lj}}^{X}$ values require only the attractive potential of $E_{\mathrm{Lj}}^{X}$ values (two-atom potentials $<0$ ) because $E_{\mathrm{D} 3}^{X}$ values include only such attractive forces. $E_{\mathrm{LJ}}^{X}$ and $E_{\mathrm{D} 3}^{X}$ values are similar (Fig. 12, $E_{\mathrm{LJ}}^{X}=E_{\mathrm{D} 3}^{X} \pm 0.73 \mathrm{~kJ} \mathrm{~mol}^{-1}, 95 \%$ confidence interval $(\mathrm{CI})$ ) for DFT-optimized H-bonded acetone at T1 and T2 sites in TON, T1-T12 sites in MFI, and the T1 site in FAU and for TS2 at the T12 site in MFI and at the T1 site in FAU (VASP, RPBE and $\mathrm{RPBE}+\mathrm{D} 3(\mathrm{BJ}))$. Such benchmarking is used here to determine the scaling factor $(\varepsilon=1.59 \pm$ $0.01 \mathrm{~kJ} \mathrm{~mol}^{-1}$; Fig. 12) in Lennard-Jones potentials, which is the same for all atoms in organic moieties or the framework (TS2, H-bonded acetone organic moieties; TON, MFI, FAU frameworks, Fig. 12), as expected from the non-specific nature of van der Waals interactions.

$E_{\mathrm{Lj}}^{A c *}$ values were calculated, without additional geometry or energy optimizations, for $\mathrm{H}-$ bonded acetone at each of the 30 distinct accessible O-atoms within the MFI framework $\left(>10^{3}\right.$ orientations sampled at each $\mathrm{O}_{\mathrm{Z}}$ atom, Section 2.6). These $E_{\mathrm{LJ}}^{A c *}$ values are similar to their corresponding DFT-optimized (VASP, RPBE $+\mathrm{D} 3(\mathrm{BJ})) E_{\mathrm{D} 3}^{A c *}$ values $\left( \pm 1.61 \mathrm{~kJ} \mathrm{~mol}^{-1}, 95 \% \mathrm{CI}\right.$; Fig. 13). Such similarities across the diverse environments within MFI voids $\left(E_{\mathrm{LJ}}^{A c *}=-82--111\right.$ $\mathrm{kJ} \mathrm{mol}^{-1}$, Fig. 13) suggest that this method allows efficient and accurate assessments of $E_{\mathrm{vdW}}^{X}$ values, even though $E_{\mathrm{LJ}}^{X}$ calculations exclude any structural relaxation in the organic moiety or the framework in response to their proximity. 


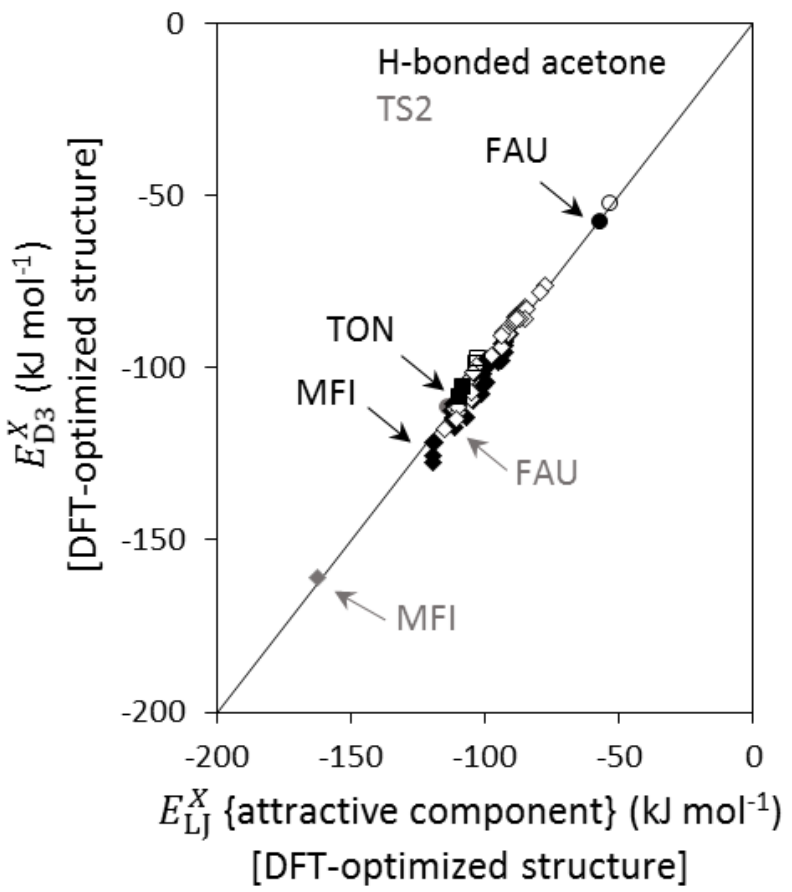

Figure 12: D3 dispersive energy corrections of optimized DFT-structures (Eq. 12) as a function of $E_{\mathrm{LJ}}$ values of the optimized DFT-structure. Structures of H-bonded acetone (black) and TS2 (gray) in MFI (diamonds), TON (squares), and FAU (circles) frameworks optimized with RPBE + D3(BJ) (filled) and RPBE (open, only H-bonded acetone). $E_{\mathrm{LJ}}^{X}$-values calculated with $\varepsilon=1.59 \mathrm{~kJ}$ $\mathrm{mol}^{-1}$ (Eq. 11). Solid line is a parity line.

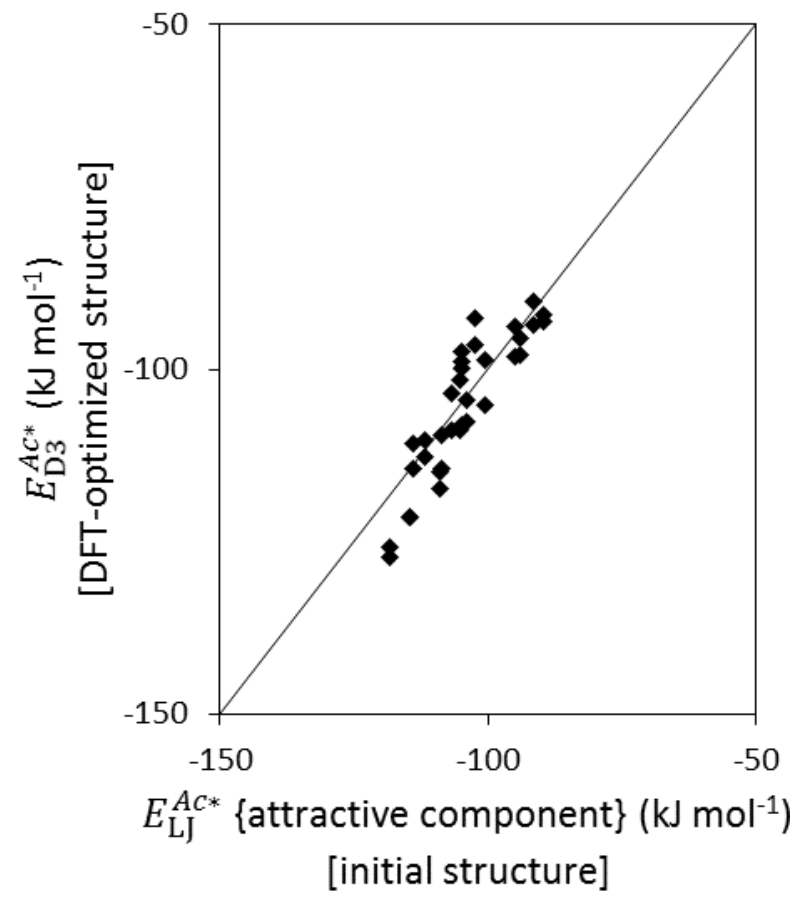

Figure 13: D3 dispersive energy corrections of optimized DFT-structures for H-bonded acetone (Eq. 12) at all distinct O-atoms of MFI as a function of $E_{\mathrm{LJ}}^{A c *}$ values of initial structures (not DFT-optimized) (VASP, RPBE + D3(BJ) PAW5). $E_{\mathrm{LJ}}^{A c *}$ values calculated with $\varepsilon=1.59 \mathrm{~kJ} \mathrm{~mol}^{-1}$ (Eq. 11). Solid line is a parity line.

The $E_{\mathrm{vdW}}^{X}$ values for TS2 and H-bonded acetone were calculated at each crystallographically-distinct $\mathrm{Al}$ location in each framework from the average of all $E_{\mathrm{LJ}}^{X}$ values $\left(>10^{3}\right.$ orientations at each $\mathrm{Al}$ location, Section 2.6) weighted by the probability of each orientation, given by $E_{\mathrm{int}, j}^{X}$, the interaction energy at each orientation, $j$ :

$$
E_{\mathrm{vdW}}^{X}=\frac{\sum_{j} E_{\mathrm{vdW}, j}^{X} \exp \left(-\frac{E_{\mathrm{int}, j}^{X}}{k_{B} T}\right)}{\sum_{j} \exp \left(-\frac{E_{\mathrm{int}, j}^{X}}{k_{B} T}\right)}
$$


These interaction energies can be dissected into electrostatic and van der Waals contributions (Eq. 25), and taken together with the assumption that the $E_{\mathrm{ES}}^{X}$ is independent of orientation due the centers of charge in each moiety being separated at a constant distance among all orientation (Section 2.6), Equation 28 becomes:

$$
E_{\mathrm{vdW}}^{X}=\frac{\sum_{j} E_{\mathrm{vdW}, j}^{X} \exp \left(-\frac{E_{\mathrm{vdW}, j}^{X}}{k_{B} T}\right)}{\sum_{j} \exp \left(-\frac{E_{\mathrm{vdW}, j}^{X}}{k_{B} T}\right)}
$$

where $E_{\mathrm{vdW}, j}^{X}$ is the only remaining energy term. These $E_{\mathrm{vdW}}^{X}$ values for TS2 and H-bonded acetone at a given T-site rigorously account for the dispersive stabilization that leads to the effects of void geometry on the condensation reactivity of protons (Eq. 26).

These calculated $\Delta E_{\mathrm{vdW}}$ values (Eq. 26) for TON, FAU, and BEA frameworks are similar at each of their respective Al T-site locations (Fig. 14), but vary among these frameworks, a consequence of local void environments that are similar at all T-sites in each structure. For example, TON consists of one-dimensional straight channels with three T-sites exposed at these channels of uniform cylindrical shape; their three $\Delta E_{\mathrm{vdW}}$ values are within $1 \mathrm{~kJ} \mathrm{~mol}^{-1}$ (Fig 14). FAU is a three-dimensional zeolite with only one T-site, which thus resides within a single local environment. BEA consists of two 12-member ring straight channels that intersect forming voids with limiting diameters similar to those of the channels (BEA, Table 1), which provide similar void environments surrounding each of the 9 distinct T-sites $\left( \pm 6.0 \mathrm{~kJ} \mathrm{~mol}^{-1}, 95 \%\right.$ CI; Fig. 14). Therefore, ensemble-averaged $\Delta E_{\mathrm{vdW}}$ values ( $\left\langle\Delta E_{\mathrm{vdW}}\right\rangle$, Eq. 27) do not depend on the locations of the $\mathrm{Al}$ atoms and their associated protons among the distinct T-sites in these frameworks.

The $\Delta E_{\mathrm{vdW}}$ values for MFI and FER frameworks, however, differ significantly among Tsite locations (Fig. 14) because of the very different local environments created by the channel 
intersections and cage-like voids within these two zeolites (Table 1). Comparisons of measured condensation rate constants with calculated $\left\langle\Delta E_{\mathrm{vdW}}\right\rangle$ values (Eq. 27) require knowledge about $\mathrm{Al}$ location in these samples, which depend on synthetic protocols and are seldom accessible to experiments $[92,93]$. Here we assume that protons (and Al) are distributed uniformly among all T-sites in the absence of experimental evidence of $\mathrm{T}$-site speciation, where $\mathrm{P}_{\mathrm{T} \text {-site, } i}$ (Eq. 27) is given by:

$$
\mathrm{P}_{\mathrm{T}-\text { site }, i}=\frac{D_{\mathrm{T}-\text { site }, \mathrm{i}}}{\sum_{j}^{N_{\mathrm{T}-\mathrm{site}}} D_{\mathrm{T}-\mathrm{site}, \mathrm{j}}}
$$

and $D_{\mathrm{T}-\text { site, }}$ represents the number of locations of each T-site, $i$, per unit cell of the framework (Table 3). Three types of uniform distributions are considered in calculating $\left\langle\Delta E_{\mathrm{vdw}}\right\rangle$ values for each framework; we consider equal probabilities (i) at all T-sites ( $\mathrm{P}_{\mathrm{T} \text {-site }}$ listed in Table 3), (ii) at T-sites with access only to channels (T4 site in MFI, T1-T3 sites in FER), and (iii) at T-sites that can access intersections in MFI and cage-like structures in FER (T1-T3 and T5-T12 sites in MFI, T4 site in FER). The resulting $\left\langle\Delta E_{\mathrm{vdW}}\right\rangle$ values provide an estimate of the sensitivity of $\left\langle\Delta E_{\mathrm{vdW}}\right\rangle$ to the distribution of $\mathrm{Al}$ locations within these frameworks (MFI, FER), and the $\left\langle\Delta E_{\mathrm{vdw}}\right\rangle$ values for distributions (ii) and (iii) are represented by the horizontal bars in Figure 15. 


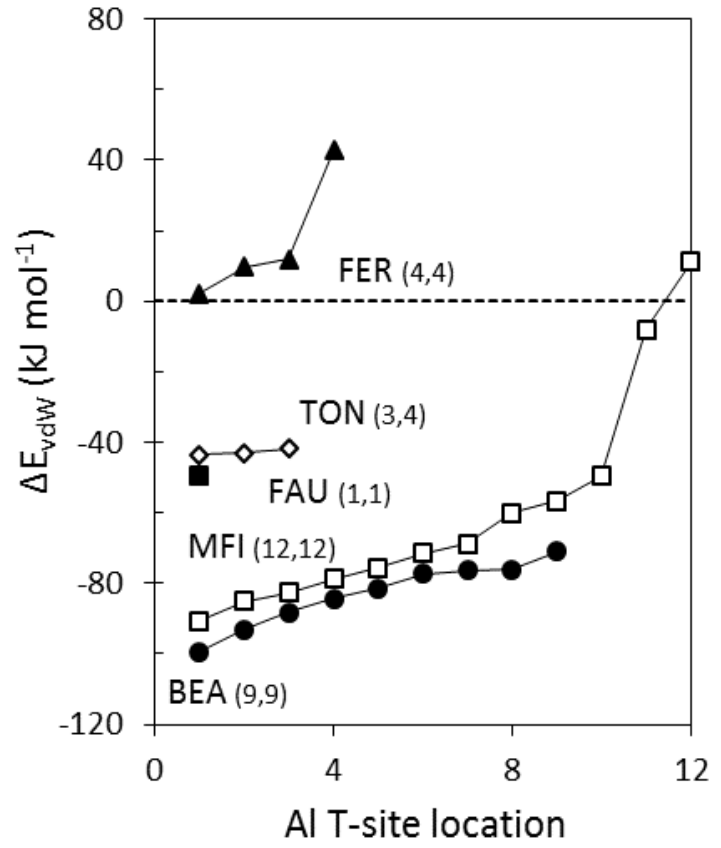

Figure 14: The differences in van der Waals interaction energy values between TS2 and $\mathrm{H}-$ bonded acetone $\left(\Delta E_{\mathrm{vdW}}\right)$ at each crystallographically unique $\mathrm{Al}$ locations in FER (closed triangles), TON (open diamonds), FAU (closed square), MFI (open squares), and BEA (closed circles) calculated by Eq. 26. Horizontal axis values are arranged by ascending $\Delta E_{\mathrm{vdW}^{-}}$ values. Values in parentheses denote the number of accessible Al locations and the total number of crystallographically unique $\mathrm{Al}$ locations in each aluminosilicate framework, respectively.

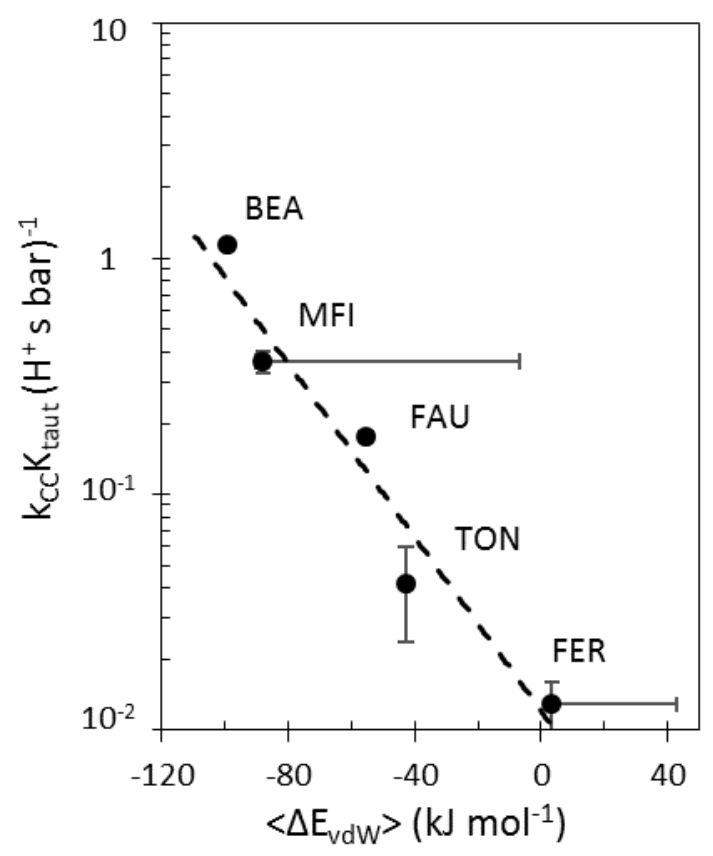

Figure 15: First-order acetone condensation rate constants (473 K, 0.1-5 $\mathrm{kPa}$ acetone, $27 \mathrm{kPa} \mathrm{H}_{2}$ ) as a function of the ensemble-averaged $\mathrm{E}_{\mathrm{vdW}}$-values $\left(\left\langle\Delta E_{\mathrm{vdW}}\right\rangle\right)$ for aluminosilicates (Eq. 27). All samples contain $\mathrm{Pt}$ (amount and location of $\mathrm{Pt}$ provided in Fig. 4 for MFI, BEA and Fig. S.4, SI for FER, TON, FAU). Vertical bars represent $95 \%$ confidence intervals of the regressed linear fits of rate data to the form of Eq. 15. Horizontal bars represent the ensemble averaging of the distinct void environments within each framework. The dashed line through the data points is a trend line.

A semi-logarithmic plot of measured condensation rate constants shows a linear increase as $\left\langle\Delta E_{\mathrm{vdW}}\right\rangle$ values become negative (Fig. 15) indicative of the exponential effects of $\left\langle\Delta E_{\mathrm{vdW}}\right\rangle$ values on reactivity (Scheme 4). These $\left\langle\Delta E_{\mathrm{vdw}}\right\rangle$ estimates also describe the differences in measured reactivities between BEA $\left(\left\langle\Delta E_{\mathrm{vdW}}\right\rangle=-99 \mathrm{~kJ} \mathrm{~mol}^{-1}\right)$ and $\mathrm{MFI}\left(\left\langle\Delta E_{\mathrm{vdW}}\right\rangle=-88 \mathrm{~kJ} \mathrm{~mol}^{-1}\right)$ frameworks, for which geometric descriptors, such as their largest cavity diameter, would have predicted similar reactivities (Fig. 11). The smaller measured rate constant (per proton) on MFI relative to BEA seems inconsistent with the greater stability of TS2 at the T-sites that reside at 
MFI intersections than in BEA (minimum $E_{\mathrm{vdW}}^{T S 2}=-185$ and $-179 \mathrm{~kJ} \mathrm{~mol}^{-1}$ for MFI and BEA, respectively; Table 3). These observations reflect the more effective stabilization of the $\mathrm{H}$ bonded acetone species in the sinusoidal channels of MFI, which are accessible to oxygen atoms vicinal to 11 of the $12 \mathrm{~T}$-sites in MFI (T11 site is the exception), relative to the stabilization of H-bonded acetone species in the larger straight channels of BEA (minimum $E_{\mathrm{vdW}}^{H-A c}=-108$ and $85 \mathrm{~kJ} \mathrm{~mol}^{-1}$ for MFI and BEA, respectively; Table 3). This increased stabilization of the precursors on MFI leads to larger free energy barriers and the lower reactivity of protons within MFI compared to BEA. These differences in $E_{\mathrm{vdW}}^{T S 2}$ and $E_{\mathrm{vdW}}^{H-A c}$ values across voids of similar size demonstrate the incomplete nature of geometric descriptors that do not account for void shape. In contrast, the methods described here account for the van der Waals stabilization energies that reflect the diverse size and shape of void environments, thus capturing the consequences of confinement for reactivity from how such interactions differ between TS and precursor structures.

Table 3: Number of each T-site per unit cell $\left(D_{\mathrm{T} \text {-site }}\right)$, T-site probability ( $\mathrm{P}_{\mathrm{T}-\text { site, }}$ Eq. 30$), E_{\mathrm{vdW}}^{T S 2}\left(\mathrm{~kJ} \mathrm{~mol}^{-1}\right.$; Eq. 29), $E_{\mathrm{vdW}}^{H-A c}$ (kJ mol ${ }^{-1}$; Eq. 29), $\Delta E_{\mathrm{vdW}}$ (kJ mol ${ }^{-1}$; Eq. 26) for each distinct Al location on (a) FER, (b) TON, (c) MFI, (d) BEA, and (e) FAU frameworks

(a) FER (4 T-sites)

\begin{tabular}{ccccccc} 
configuration & Al T-site & $D_{\text {T-site }}$ & $\mathrm{P}_{\text {T-site }}$ & $E_{\mathrm{vdW}}^{T S 2}$ & $E_{\mathrm{vdW}}^{H-A c}$ & $\Delta E_{\mathrm{vdW}}$ \\
\hline 1 & $\mathrm{~A} 11$ & 16 & 0.444 & -98 & -100 & 2 \\
2 & $\mathrm{~A} 12$ & 8 & 0.222 & -90 & -102 & 12 \\
3 & $\mathrm{Al}$ & 8 & 0.222 & -100 & -110 & 10 \\
4 & $\mathrm{~A} 14$ & 4 & 0.111 & -59 & -102 & 43 \\
\hline
\end{tabular}

(b) TON (4 T-sites)

\begin{tabular}{ccccccc} 
configuration & $\mathrm{Al} \mathrm{T}$-site & $D_{\mathrm{T}-\text { site }}$ & $\mathrm{P}_{\mathrm{T}-\text { site }}$ & $E_{\mathrm{vdW}}^{T S 2}$ & $E_{\mathrm{vdW}}^{H-A c}$ & $\Delta E_{\mathrm{vdW}}$ \\
\hline 1 & $\mathrm{~A} 11$ & 8 & 0.333 & -138 & -95 & -43 \\
2 & $\mathrm{~A} 12$ & 8 & 0.333 & -139 & -97 & -42 \\
3 & $\mathrm{~A} 13$ & 4 & 0.167 & -141 & -98 & -43 \\
4 & $\mathrm{Al}$ & 4 & 0.167 & -- & -- & -- \\
\hline
\end{tabular}

(c) MFI (12 T-sites) 


\begin{tabular}{ccccccc} 
configuration & Al T-site & $D_{\text {T-site }}$ & $\mathrm{P}_{\text {T-site }}$ & $E_{\mathrm{vdW}}^{T S 2}$ & $E_{\mathrm{vdW}}^{H-A c}$ & $\Delta E_{\mathrm{vdW}}$ \\
\hline 1 & $\mathrm{~A} 11$ & 8 & 0.083 & -181 & -99 & -82 \\
2 & $\mathrm{~A} 12$ & 8 & 0.083 & -150 & -100 & -50 \\
3 & $\mathrm{~A} 13$ & 8 & 0.083 & -167 & -107 & -60 \\
4 & $\mathrm{Al} 4$ & 8 & 0.083 & -114 & -106 & -8 \\
5 & $\mathrm{~A} 15$ & 8 & 0.083 & -181 & -102 & -79 \\
6 & $\mathrm{Al}$ & 8 & 0.083 & -183 & -108 & -75 \\
7 & $\mathrm{~A} 17$ & 8 & 0.083 & -163 & -107 & -56 \\
8 & $\mathrm{Al}$ & 8 & 0.083 & -82 & -93 & 11 \\
9 & $\mathrm{~A} 19$ & 8 & 0.083 & -170 & -101 & -69 \\
10 & $\mathrm{Al10}$ & 8 & 0.083 & -169 & -98 & -71 \\
11 & $\mathrm{All1}$ & 8 & 0.083 & -185 & -95 & -90 \\
12 & $\mathrm{Al12}$ & 8 & 0.083 & -185 & -100 & -85
\end{tabular}

(d) BEA (9 T-sites)

\begin{tabular}{|c|c|c|c|c|c|c|}
\hline configuration & Al T-site & $D_{\text {T-site }}$ & $\mathrm{P}_{\text {T-site }}$ & $E_{\mathrm{vdW}}^{T S 2}$ & $E_{\mathrm{vdW}}^{H-A c}$ & $\Delta E_{\mathrm{vdW}}$ \\
\hline 1 & Al1 & 8 & 0.125 & -155 & -84 & -71 \\
\hline 2 & $\mathrm{~A} 12$ & 8 & 0.125 & -162 & -85 & -77 \\
\hline 3 & $\mathrm{~A} 13$ & 8 & 0.125 & -170 & -82 & -92 \\
\hline 4 & Al4 & 8 & 0.125 & -165 & -81 & -84 \\
\hline 5 & A15 & 8 & 0.125 & -158 & -82 & -76 \\
\hline 6 & $\mathrm{Al} 6$ & 8 & 0.125 & -179 & -80 & -99 \\
\hline 7 & Al7 & 8 & 0.125 & -161 & -85 & -76 \\
\hline 8 & $\mathrm{~A} 18$ & 4 & 0.0625 & -173 & -80 & -93 \\
\hline 9 & $\mathrm{~A} 19$ & 4 & 0.0625 & -165 & -84 & -81 \\
\hline \multicolumn{7}{|c|}{ (e) FAU (1 T-site) } \\
\hline configuration & Al T-site & $D_{\text {T-site }}$ & $\mathrm{P}_{\mathrm{T} \text {-site }}$ & $E_{\mathrm{vdW}}^{T S 2}$ & $E_{\mathrm{vdW}}^{H-A c}$ & $\Delta E_{\mathrm{vdW}}$ \\
\hline 1 & Al1 & 192 & 1.00 & -113 & -58 & -55 \\
\hline
\end{tabular}

\section{Conclusions}

We present the elementary steps and assess their kinetic relevance for acetone condensation on a range of microporous and mesoporous aluminosilicates (FER, TON, MFI, BEA, FAU, and MCM-41) using kinetic, spectroscopic, and isotopic data that are supported by theoretical simulations. Rapid catalyst deactivation that limits the study and application of solid acid catalysts for aldol condensation was inhibited through the addition of $\mathrm{Pt}$ - as physical mixtures with the acid catalyst or ion-exchanged into the crystals - and $\mathrm{H}_{2}$ to hydrogenate $\mathrm{C}=\mathrm{C}$ 
bonds in the reactive $\alpha, \beta$-unsaturated intermediates (MO). Selective titrations of the active site with 2,6-di-tert-butyl pyridine during catalysis suggest that protons account for all of the reactivity and allow assessment of the number of active protons in each sample, which is required for rigorous normalization of measured rates and comparisons with DFT-simulated free energy barriers.

Our experimental work, in tandem with our DFT-calculations benchmark a descriptor of the catalytic consequences of the confining void environment for reactivity. Lennard-Jones potentials describing the interactions between framework $\mathrm{O}_{\mathrm{Z}}$ atoms and atoms of the relevant organic moieties (transition state and precursors) provide valuable insights into the effects of the confining void by quantifying the van der Waals stabilization energy proffered by the diverse sizes and shapes of the void environments throughout aluminosilicate frameworks. The methods described herein require DFT-estimated structures of the organic moieties at a single T-atom location (TS2 and H-bonded acetone; MFI Al T12 site, VASP, RPBE + D3(BJ)) and rigorous averaging of the stabilization energies at each $\mathrm{T}$-atom location to allow comparisons with measured rate constants (per proton). The descriptor of void environment used here ( $\left.\left\langle\Delta E_{\mathrm{vdw}}\right\rangle\right)$ offers significant advances in the current understanding of the catalytic effects of confining voids by providing (i) consideration of both attractive and repulsive interactions and, thus, estimations of van der Waals stabilization without full DFT-optimizations, (ii) efficient determination of reasonable initial structures for DFT-simulations, and (iii) extension to other acid-catalyzed reactions with known structures of the relevant transition states and precursors. 


\section{Acknowledgements}

The authors acknowledge the financial support of BP, p.l.c. for this work as part of the BP Conversion Consortium $\left(\mathrm{BP}-\mathrm{XC}^{2}\right)$; the technical discussions with Drs. Drew Braden, Eric Doskocil, and John Shabaker (BP, p.l.c.), Dr. Shuai Wang, Dr. David Hibbitts, and Michele Sarazen (University of California, Berkeley), and Prof. Matthew Neurock (University of Minnesota); and the proton counts of the FER sample performed by Dr. Andrew Jones and Gina Noh (University of California, Berkeley). Computational facilities were provided by BP High Performance Computing (BP, p.l.c.) and by the Extreme Science and Engineering Discovery Environment (XSEDE), which is supported by the National Science Foundation (grant number: CHE-140066). 


\section{References}

1. Taarning, E., et al., Zeolite-catalyzed biomass conversion to fuels and chemicals. Energy \& Environmental Science, 2011. 4(3): p. 793-793.

2. Kumar, P., et al., Methods for Pretreatment of Lignocellulosic Biomass for Efficient Hydrolysis and Biofuel Production. Industrial \& Engineering Chemistry Research, 2009. 48: p. 3713-3729.

3. Bridgwater, A., Renewable fuels and chemicals by thermal processing of biomass. Chemical Engineering Journal, 2003. 91(2-3): p. 87-102.

4. Resasco, D., What should we demand from catalysts responsible for upgrading biomass pyrolysis oil? The Journal of Physical Chemistry Letters, 2011. 2: p. 2294.

5. Corma, A., et al., Production of High-Quality Diesel from Biomass Waste Products. Angewandte Chemie (International ed.), 2011. 50(10): p. 2375-2378.

6. Di Cosimo, J.I. and C.R. Apesteguía, Study of the catalyst deactivation in the basecatalyzed oligomerization of acetone. Journal of Molecular Catalysis A: Chemical, 1998. 130(1-2): p. 177-185.

7. Luo, S. and J.L. Falconer, Aldol condensation of acetaldehyde to form high molecular weight compounds on TiO2. Catalysis letters, 1999. 57: p. 89-93.

8. Sun, J., et al., Key Roles of Lewis Acid-Base Pairs on ZnxZryOz in Direct Ethanol/Acetone to Isobutene Conversion. Journal of the American Chemical Society, 2016. 138(2): p. 507-517.

9. Sad, M.E., M. Neurock, and E. Iglesia, Formation of $\mathrm{C}-\mathrm{C}$ and $\mathrm{C}-\mathrm{O}$ bonds and oxygen removal in reactions of alkanediols, alkanols, and alkanals on copper catalysts. Journal of the American Chemical Society, 2011. 133(50): p. 20384-98.

10. Biaglow, A.I., et al., A 13C NMR Study of the Condensation Chemistry of Acetone and Acetaldehyde Adsorbed at the Brønsted Acid Sites in H-ZSM-5. Journal of Catalysis, 1995. 151(2): p. 373-384.

11. Lin, F. and Y.-H.C. Chin, Mechanism of intra- and inter-molecular CC bond formation of propanal on Brønsted acid sites contained within MFI zeolites. Journal of Catalysis, 2014. 311: p. 244-256.

12. Gounder, R. and E. Iglesia, The catalytic diversity of zeolites: confinement and solvation effects within voids of molecular dimensions. Chemical communications (Cambridge, England), 2013. 49(34): p. 3491-509.

13. Jones, A.J. and E. Iglesia, The Strength of Bronsted Acid Sites in Microporous Aluminosilicates. ACS Catalysis, 2015. 5(10): p. 5741-5755.

14. Kubelkovå, L., et al., Acetone Conversion and Deactivation of Zeolites, in Studies in Surface Science and Catalysis, P.A. Jacobs and R.A.v. Santen, Editors. 1989, Elsevier. p. 1203-1212.

15. Kubelková, L. and J. Nováková, Deactivation and regeneration of HZSM-5 zeolite in acetone conversion: Properties of OH groups. Journal of Molecular Catalysis, 1992. 75(1): p. 53-62.

16. Ungureanu, A., et al., Aldol condensation of aldehydes over semicrystalline zeoliticmesoporous UL-ZSM-5. Microporous and Mesoporous Materials, 2005. 84(1-3): p. 283296. 
17. Konno, H., et al., Characterization and catalytic performance of modified nano-scale ZSM-5 for the acetone-to-olefins reaction. Applied Catalysis A: General, 2014. 475: p. 127-133.

18. Tago, T., et al., Selective synthesis for light olefins from acetone over ZSM-5 zeolites with nano- and macro-crystal sizes. Applied Catalysis A: General, 2011. 403(1-2): p. 183-191.

19. Panov, A.G. and J.J. Fripiat, Acetone Condensation Reaction on Acid Catalysts. Journal of Catalysis, 1998. 178(1): p. 188-197.

20. Hutchings, G., et al., Acetone conversion to isobutene in high selectivity using zeolite $\beta$ catalyst. Catalysis letters, 1993. 21(1-2): p. 49-53.

21. Tago, T., et al., Selective production of isobutylene from acetone over alkali metal ionexchanged BEA zeolites. Catalysis Today, 2011. 164(1): p. 158-162.

22. Yang, P., et al., One-step synthesis of methyl isobutyl ketone from acetone over Pd/MCM22 zeolites. Journal of Molecular Catalysis A: Chemical, 2007. 272(1-2): p. 75-83.

23. Panov, A. and J. Fripiat, Poisoning of aldol condensation reaction with $\mathrm{H} 2 \mathrm{O}$ on acid catalysts. Catalysis letters, 1999. 57(1-2): p. 25-32.

24. Dumitriu, E., et al., The aldol condensation of lower aldehydes over MFI zeolites with different acidic properties. Microporous and Mesoporous Materials, 2001. 43(3): p. 341359.

25. Gayubo, A.G. and A.T. Aguayo, Transformation of oxygenate components of biomass pyrolysis oil on a HZSM-5 zeolite. II. Aldehydes, ketones, and acids. Industrial \& ..., 2004: p. 2619-2626.

26. Salvapati, G.S., K.V. Ramanamurty, and M. Janardanarao, Selective catalytic selfcondensation of acetone. Journal of Molecular Catalysis, 1989. 54(1): p. 9-30.

27. Melo, L., et al., Acetone transformation into methyl isobutyl ketone over Pt/HMFI catalysts. IV. Effect of density and strength of the acidic sites. Catalysis letters, 1999. 60: p. 217-222.

28. Melo, L., et al., Effect of the metallic/acid site (nPt/nA) ratio on the transformation of acetone towards methyl isobutyl ketone. Catalysis letters, 1997. 44: p. 201-204.

29. Melo, L., et al., Synthesis of methyl isobutyl ketone using Pt-H ZSM5 bifunctional catalysts. III. Effect of the nPt/nA parameter on the xPt-H ZSM5 (y) catalysts. Catalysis letters, 1998. 51: p. 207-212.

30. Melo, L., et al., Acetone transformation over Pt/H[Al]ZSM5 and Pt/H[Ga]ZSM5 catalysts. Journal of Molecular Catalysis A: Chemical, 2002. 177(2): p. 281-287.

31. Vannice, M. and B. Sen, Metal-support effects on the intramolecular selectivity of crotonaldehyde hydrogenation over platinum. Journal of Catalysis, 1989. 78(115): p. 6578.

32. Marinelli, T., S. Nabuurs, and V. Ponec, Activity and Selectivity in the Reactions of Substituted $\alpha, \beta$-Unsaturated Aldehydes. Journal of Catalysis, 1995. 151(2): p. 431-438.

33. Grimme, S., S. Ehrlich, and L. Goerigk, Effect of the Damping Function in Dispersion Corrected Density Functional Theory. Journal of computational chemistry, 2011. 32(7): p. $1456-1465$.

34. Grimme, S., et al., A consistent and accurate ab initio parametrization of density functional dispersion correction (DFT-D) for the 94 elements $\mathrm{H}-\mathrm{Pu}$. The Journal of Chemical Physics, 2010. 132(15): p. 154104. 
35. First, E.L., et al., Computational characterization of zeolite porous networks: an automated approach. Physical chemistry chemical physics : PCCP, 2011. 13(38): p. 17339-58.

36. Barri, S.A.I. and D. Young, Crystalline zincosilicate, E.P. Office, Editor. 1984, Google Patents: Great Britain.

37. Ball, W.J., S.A.I. Barri, and D. Young, Improved method of preparing crystalline aluminosilicates, E.P. Office, Editor. 1986: Great Britain.

38. Skeels, G.W. and D.W. Breck, Silicon substituted Y zeolite composition LZ-210 1987, Union Carbide Corporation: United States. p. 26.

39. Corma, A., V. Fornés, and F. Rey, Extraction of extra-framework aluminium in ultrastable $\mathrm{Y}$ zeolites by $\left(\mathrm{NH}_{4}\right)_{2} \mathrm{SiF}_{6}$ treatments. Applied Catalysis, 1990. 59: p. 267-274.

40. Gounder, R., et al., Solvation and acid strength effects on catalysis by faujasite zeolites. Journal of Catalysis, 2012. 286: p. 214 - 223.

41. Baerlocher, C. and L.B. McCusker. Database of Zeolite Structures. February 6, 2016]; Available from: http://www.iza-structure.org/databases/.

42. Jones, A.J., et al., Acid strength and solvation in catalysis by MFI zeolites and effects of the identity, concentration and location of framework heteroatoms. Journal of Catalysis, 2014. 312: p. 58-68.

43. Jones, A.J., S.I. Zones, and E. Iglesia, Implications of Transition State Confinement within Small Voids for Acid Catalysis. The Journal of Physical Chemistry ..., 2014. 118(31): p. 17787-17800.

44. Sarazen, M., E. Doskocil, and E. Iglesia, The Effects of Void Environment and Acid Strength on Alkene Oligomerization Selectivity. ACS Catalysis, 2016. 6: p. 7059.

45. Levenspiel, O., Experimental Search for a Simple Rate Equation to Describe Deactivating Porous Catalyst Particles. Journal of Catalysis, 1972. 25: p. 265-272.

46. Zhao, Y.H., M.H. Abraham, and A.M. Zissimos, Fast calculation of van der Waals volume as a sum of atomic and bond contributions and its application to drug compounds. The Journal of organic chemistry, 2003. 68(19): p. 7368-7373.

47. Foster, M.D., et al., A geometric solution to the largest-free-sphere problem in zeolite frameworks. Microporous and Mesoporous Materials, 2006. 90(1-3): p. 32-38.

48. Kresse, G. and J. Hafner, Ab initio molecular dynamics for liquid metals. Physical Review B, 1993. 47: p. 558-561.

49. Kresse, G. and J. Hafner, Ab initio molecular-dynamics simulation of the liquid-metalamorphous-semiconductor transition in germanium. Physical Review B, 1994. 49: p. 14251-14269.

50. Kresse, G. and J. Furthmüller, Efficiency of ab-initio total energy calculations for metals and semiconductors using a plane-wave basis set. Computational Materials Science, 1996. 6: p. 15-50.

51. Kresse, G. and J. Furthmüller, Efficient iterative schemes for ab initio total-energy calculations using a plane-wave basis set. Physical Review B, 1996. 54: p. 11169-11186.

52. Blöchl, P.E., Projector augmented-wave method. Physical Review B, 1994. 50: p. 1795317979.

53. Kresse, G. and D. Joubert, From ultrasoft pseudopotentials to the projector augmentedwave method. Physical Review B, 1999. 59: p. 1758-1775.

54. Yang, K., et al., Tests of the RPBE, revPBE, tau-HCTHhyb, omegaB97X-D, and MOHLYP density functional approximations and 29 others against representative 
databases for diverse bond energies and barrier heights in catalysis. The Journal of chemical physics, 2010. 132: p. 164117.

55. Perdew, J.P., K. Burke, and M. Ernzerhof, Generalized Gradient Approximation Made Simple. Physical Review Letters, 1996. 77(18): p. 3865-3868.

56. Lee, K., et al., Higher-accuracy van der Waals density functional. Physical Review B, 2010. 82: p. 081101.

57. Klimeš, J., D.R. Bowler, and A. Michaelides, Van der Waals density functionals applied to solids. Physical Review B, 2011. 83(19): p. 195131.

58. Román-Pérez, G. and J.M. Soler, Efficient Implementation of a van der Waals Density Functional: Application to Double-Wall Carbon Nanotubes. Physical Review Letters, 2009. 103(9): p. 096102.

59. Dion, M., et al., Van der Waals Density Functional for General Geometries. Physical Review Letters, 2004. 92(24): p. 246401.

60. van Koningsveld, H., H. van Bekkum, and J.C. Jansen, On the location and disorder of the tetrapropylammonium (TPA) ion in zeolite ZSM-5 with improved framework accuracy. Acta Crystallographica Section B Structural Science, 1987. 43: p. 127-132.

61. Olson, D.H., et al., Crystal structure and structure-related properties of ZSM-5. The Journal of Physical Chemistry, 1981. 85: p. 2238-2243.

62. Momma, K. and F. Izumi, VESTA: a three-dimensional visualization system for electronic and structural analysis. Journal of Applied Crystallography, 2008. 41: p. 653658.

63. Jónsson, H., G. Mills, and K.W. Jacobsen, Nudged elastic band method for finding minimum energy paths of transitions, in Classical and Quantum Dynamics in Condensed Phase Simulations, B.J. Berne, G. Ciccotti, and D.F. Coker, Editors. 1998, World Scientific. p. 385-404.

64. Henkelman, G. and H. Jónsson, A dimer method for finding saddle points on high dimensional potential surfaces using only first derivatives. The Journal of Chemical Physics, 1999. 111(15): p. 7010.

65. Deshlahra, P., et al., Mechanistic Details and Reactivity Descriptors in Oxidation and Acid Catalysis of Methanol. ACS Catalysis, 2015. 5(2): p. 666-682.

66. Campbell, C.T. and J.R.V. Sellers, Enthalpies and Entropies of Adsorption on WellDefined Oxide Surfaces : Experimental Measurements. Chemical reviews, 2013. 113: p. 4106-4135.

67. Eyring, H., The Activated Complex in Chemical Reactions. The Journal of Chemical Physics, 1935. 3(2): p. 107-115.

68. Evans, M.G. and M. Polanyi, Some applications of the transition state method to the calculation of reaction velocities, especially in solution. Transactions of the Faraday Society, 1935. 31: p. 875-894.

69. Lennard-Jones, J.E., Cohesion. The Proceedings of the Physical Society, 1931. 43(5): p. 461-482.

70. Lennard-Jones, J.E., On the Determination of Molecular Fields - II. From the Equation of State of a Gas. Proceedings of the Royal Society of London, 1924. 106(738): p. 463-477.

71. Bondi, A., van der Waals Volumes and Radii. The Journal of Physical Chemistry, 1964. 68(3): p. 441-451. 
72. Löwdin, P.-O., On the Non-Orthogonality Problem Connected with the Use of Atomic Wave Functions in the Theory of Molecules and Crystals. The Journal of Chemical Physics, 1950. 18(3): p. 365-375.

73. Qian, X., et al., Quasiatomic orbitals for ab initio tight-binding analysis. Physical Review B - Condensed Matter and Materials Physics, 2008. 78(24): p. 1-22.

74. Lu, W.C., et al., Molecule intrinsic minimal basis sets. I. Exact resolution of ab initio optimized molecular orbitals in terms of deformed atomic minimal-basis orbitals. The Journal of chemical physics, 2004. 120(6): p. 2629-2637.

75. Lu, W.C., et al., Representation of electronic structures in crystals in terms of highly localized quasiatomic minimal basis orbitals. Physical Review B - Condensed Matter and Materials Physics, 2004. 70(4): p. 1-4.

76. Chan, T.L., et al., Highly localized quasiatomic minimal basis orbitals for Mo from ab initio calculations. Physical Review B - Condensed Matter and Materials Physics, 2007. 76(20): p. 1-10.

77. Deserno, M., How to generate equidistributed points on the surface of a sphere, M.-P.I.f. Polymerforshung, Editor. 2004.

78. Lee, J.W., J.B. Butt, and D.M. Downing, Kinetic, transport, and deactivation rate interactions on steady state and transient responses in heterogeneous catalysis. AIChE Journal, 1978. 24(2): p. 212-222.

79. Wolf, E.E. and E.E. Petersen, On the kinetics of self-poisoning catalytic reactions. Journal of Catalysis, 1977. 47(1): p. 28-32.

80. Baertsch, C.D., et al., Genesis of Brønsted Acid Sites during Dehydration of 2-Butanol on Tungsten Oxide Catalysts. Journal of Catalysis, 2002. 205: p. 44-57.

81. Boekfa, B., et al., Adsorption and Tautomerization Reaction of Acetone on Acidic Zeolites: The Confinement Effect in Different Types of Zeolites. The Journal of Physical Chemistry C, 2010. 114(35): p. 15061-15067.

82. Pelmenschikov, A., et al., $(A, B, C)$ triplet of infrared $\mathrm{OH}$ bands of zeolitic $\mathrm{H}$-complexes. Journal of physical chemistry, 1995. 99(11): p. 3612-3617.

83. Lamberti, C., et al., Probing the surfaces of heterogeneous catalysts by in situ IR spectroscopy. Chemical Society reviews, 2010. 39(12): p. 4951-5001.

84. Parker, L.M., D.M. Bibby, and G.R. Burns, FTIR spectra of bases sorbed on H+ZSM-5 A study of hydrogen bonding, P.A. Jacobs and R. van Santen, Editors. 1989, Elsevier. p. 963-972.

85. Kubelková, L., J. Čejka, and J. Nováková, Surface reactivity of ZSM-5 zeolites in interaction with ketones at ambient temperature (a FT-i.r. study). Zeolites, 1991. 11(1): p. 48-53.

86. Crossee, P. and J.H. Schachtschneider, Vibrational analysis of acetone, acetaldehyde, and formaldehyde. The Journal of chemical physics, 1966. 44(97): p. 97-11.

87. Pimentel, G.C. and A.L. McClellan, Hydrogen Bonding. Annual Review of Physical Chemistry, 1971. 22: p. 347-385.

88. Xu, M., W. Wang, and M. Hunger, Formation of acetone enol on acidic zeolite ZSM-5 evidenced by H/D exchange. Chemical communications (Cambridge, England), 2003(6): p. 722-3.

89. Macht, J., R.T. Carr, and E. Iglesia, Consequences of Acid Strength for Isomerization and Elimination Catalysis on Solid Acids. Journal of the American Chemical Society, 2009. 131: p. 6554-6565. 
90. Carr, R.T., M. Neurock, and E. Iglesia, Catalytic consequences of acid strength in the conversion of methanl to dimethyl ether. Journal of Catalysis, 2011. 278: p. 78-93.

91. Deshlahra, P., R.T. Carr, and E. Iglesia, Ionic and Covalent Stabilization of Intermediates and Transition States in Catalysis by Solid Acids. Journal of the American Chemical Society, 2014. 136: p. 15229-15247.

92. Sklenak, S., et al., Aluminum siting in silicon-rich zeolite frameworks: A combined highresolution 27Al NMR spectroscopy and quantum mechanics/molecular mechanics study of ZSM-5. Angewandte Chemie - International Edition, 2007. 46(38): p. 7286-7289.

93. Cejka, J., et al., Zeolite-based materials for novel catalytic applications: Opportunities, perspectives and open problems. Catalysis Today, 2012. 179(1): p. 2-15. 